\title{
El huésped no invitado del TLCAN: China y la desintegración del comercio en América del Norte
}

\author{
Enrique Dussel Peters y Kevin P. Gallagher
}

RESUMEN

En este trabajo se examina en qué medida el ingreso de China a la Organización Mundial del Comercio (OMC) en 2001 y el consiguiente aumento de las exportaciones mundiales afectaron a la composición del comercio entre los Estados Unidos de América y México hasta 2009. Los autores hallaron que el ingreso de China tuvo una gran repercusión en las relaciones comerciales entre esos dos países norteamericanos, al reemplazar y desplazar a muchos de los baluartes de sus exportaciones que existían antes del ingreso chino a la OMC y después de la primera etapa del Tratado de Libre Comercio de América del Norte (TLCAN) (1994-2000). Sobre la base de esta investigación, los autores sugieren una variedad de opciones de políticas para revitalizar el comercio entre los Estados Unidos de América y México y cooperar con China en la economía mundial.

PALABRAS CLAVE

CLASIFICACIÓN JEL

AUTORES
Comercio internacional, China, relaciones económicas internacionales, libre comercio, México, Estados Unidos, nafta, política comercial, estudios de casos, industria textil, industria automotriz

$\mathrm{O} 11, \mathrm{O} 24, \mathrm{O} 53, \mathrm{O} 54$

Enrique Dussel Peters es profesor de la Facultad de Economía de La Universidad Nacional Autónoma de México (unAm) y Director del Centro de Estudios China-México. dussel@unam.mx

Kevin P. Gallagher es profesor adjunto de Relaciones Internacionales de la Universidad de Boston y Codirector de la Global Economic Governance Initiative. kpg@bu.edu 


\section{I}

\section{Introducción}

La celebración del Tratado de Libre Comercio de América del Norte (TLCAN) entre México, los Estados Unidos de América y el Canadá estuvo rodeada de promesas, que incluían halagüeñas previsiones de crecimiento de las exportaciones, el empleo y el producto interno bruto (PIB) tanto en México como en los Estados Unidos de América, los dos países en que se concentra este trabajo. De hecho, ese era el resultado previsto por la teoría tradicional, pues el acuerdo permitía que cada nación se especializara en los sectores en que gozaba de mayores ventajas comparativas. Si bien el tratado produciría nuevos ganadores y perdedores, había consenso en que las ganancias superarían a las pérdidas, ofreciendo la posibilidad de que los ganadores compensaran a los perdedores y mejorara de ese modo la situación de todos los miembros. Sin embargo, esos modelos suponían - entre otras cosas- que los acuerdos comerciales fuera del TLCAN se mantendrían constantes. En 1994, ninguno de los análisis o modelos reflejaba la preocupación de que China pudiera ingresar a la Organización Mundial del Comercio (OMC) en 2001, con ventajas comparativas en algunos sectores muy apreciados tanto en los Estados Unidos de América como en México.

En el presente trabajo se analiza cómo el ascenso de China plantea una amenaza competitiva para el comercio entre los Estados Unidos de América y México y el TLCAN como bloque comercial. El artículo se divide en cinco secciones, incluida esta breve Introducción. Mientras que en la segunda sección se estudia la literatura sobre el TLCAN y sus efectos esperados en la economía de la región, en la tercera sección se presenta un análisis cuantitativo de la penetración china en los mercados de importación de los miembros del TLCAN en México y los Estados Unidos de América. En la cuarta sección se presentan los resultados de dos estudios de caso referidos a la cadena hilo-textiles-confección y a la cadena autopartes-automotriz; finalmente, en la última sección se resumen los principales hallazgos y se realizan sugerencias para futuras investigaciones y medidas de políticas.

\section{II}

\section{Estudio de la literatura}

El TLCAN ha sido un tema controvertido durante más de 20 años. En general, se afirmaba que este acuerdo produciría beneficios económicos para todas las partes y que sus efectos serían relativamente mayores en México (Comisión de Comercio Internacional de los Estados Unidos, 1992). La proximidad geográfica y el nivel de integración con México hacían que el acuerdo fuera muy atractivo para los Estados Unidos de América (Erzan y Yeats, 1992). Según la Oficina de Presupuesto del Congreso (Сво, por sus siglas en inglés) de los Estados Unidos, la economía mexicana podría crecer entre un $6 \%$ y un $12 \%$ gracias al TLCAN, mientras que las previsiones relativas a la economía estadounidense eran de alrededor del 0,25\% (сво, 1993; Kehoe, 1994). Según los analistas, el acuerdo no provocaría una gran pérdida de empleos en los Estados Unidos de América - tal vez medio millón de puestos de trabajo en más de una década (Сво, 1993) — y si bien conduciría a un aumento del salario medio en ese país, tendría escasos o nulos efectos en la situación de los trabajadores de bajos salarios (Burfisher, Robinson y Thierfelder, 2001). De hecho, en varios modelos se preveía un superávit cada vez mayor en la balanza comercial de los Estados Unidos de América con México. De acuerdo con las previsiones más audaces, merced al TLCAN las exportaciones estadounidenses a México continuarían aventajando a las exportaciones mexicanas a los Estados Unidos de América, y conducirían a un superávit en la balanza comercial estadounidense con México de alrededor de 7.000 millones de dólares a 9.000 millones de dólares por año hasta 1995, que se elevaría a entre 9.000 millones de dólares y 12.000 millones de dólares en el período 2000-2010 (Hufbauer y Schott, 1993, pág. 14).

En la época de su celebración, se preveía que el TLCAN tendría repercusiones en varios otros ámbitos en los dos países examinados. En primer lugar, en la mayoría de 
los análisis se asumió que el acuerdo produciría efectos positivos generales en las exportaciones mexicanas a largo plazo, sobre todo en aquellas dirigidas a los Estados Unidos de América, argumento basado en gran medida en los efectos positivos y automáticos del libre comercio en el crecimiento.

En segundo lugar, algunos autores subrayaron la necesidad de implementar reformas generales y sectoriales a corto y mediano plazo en México y la posibilidad de efectos negativos en algunos sectores específicos de ese país. Las autoridades de algunas naciones fuera del TLCAN manifestaron preocupación porque las normas de origen del acuerdo eliminarían algunas ventajas comparativas de los socios comerciales que no formaran parte del TLCAN y producirían una desviación del comercio. Desde este punto de vista, los tres miembros del tratado podrían eventualmente sufrir pérdidas de bienestar debido al aumento de los precios relacionado con las normas de origen. La posible adhesión de otros países solo se discutió en los años noventa con respecto a Chile y el tema no se ha retomado desde entonces. La eventual repercusión de las actividades comerciales de otras naciones -incluidas las asiáticas y en particular Chinano se examinó seriamente durante las negociaciones que condujeron a la firma del TLCAN (Dussel Peters, 2000). Para los "fundadores" del tratado, este constituía una estrategia activa y ofensiva con relación al mercado mundial y no una "fortaleza" o defensa contra terceros países. Esa visión coincidió con las expectativas en la primera etapa del TLCAN.

En tercer lugar, según varios autores, el acuerdo de libre comercio garantizaría las exportaciones mexicanas a los Estados Unidos de América a largo plazo. Algunos de ellos (Hufbauer y Schott, 1993; Weintraub, 1991) destacaron además que la eficiencia de México mejoraría debido a que el TLCAN incluía regímenes como el de derechos de propiedad intelectual, eliminaba los requisitos de valor agregado nacional e incorporaba explícitamente a los sectores de servicios y transporte. La sustitución de las cuotas con aranceles en sectores específicos, la eliminación de aranceles a largo plazo, el trato nacional para inversiones y empresas regionales, la inclusión de estándares laborales y ambientales como acuerdos complementarios y una noción general de complementariedad entre México y los Estados Unidos de América alimentaron las expectativas de resultados positivos para México en general y para la industria manufacturera y los servicios en particular. No obstante, los resultados previstos en el sector agrícola del país azteca eran mixtos y negativos. De ese modo, la integración del TLCAN y el libre comercio, desde una perspectiva teórica, habrían surtido efectos positivos en las exportaciones, el flujo de inversión extranjera directa (IED), el empleo y los salarios mexicanos (Hufbauer y Schott, 1993) y, por tal motivo, las expectativas políticas eran extremadamente altas ${ }^{1}$.

En cuarto lugar, con respecto a los efectos sectoriales en la economía mexicana, es importante diferenciar entre los efectos a corto y largo plazo. Mientras que en casi todos los análisis se subrayaba la necesidad de hacer profundas reformas en todos los sectores de la economía - también como resultado de la liberalización de las importaciones y los flujos de capital—, existía un amplio consenso sobre los beneficios del TLCAN para el sector manufacturero en términos de exportaciones, empleo, salarios y crecimiento de la productividad ${ }^{2}$. Otros autores destacaron que la socioeconomía mexicana se inclinaría aún más a los procesos de maquiladora (Kopinak, 1993), con el consiguiente empeoramiento de la calidad del empleo y el medio ambiente ${ }^{3}$. Sin embargo, también había consenso en que los sectores agrícola y de servicios mexicanos, como el sector bancario, serían los más perjudicados en el marco del TLCAN (Arroyo Picard y otros, 1993; Grinspun y Cameron, 1993; VanGrasstek y Vega, 1992).

Solo unos pocos autores sugirieron que ambos países podrían sufrir un impacto general negativo en materia de

\footnotetext{
1 "El Tratado significa más empleo y mejor pagado para los mexicanos. Esto es lo fundamental; y es así, porque vendrán más capitales, más inversión, que quiere decir más oportunidades de empleo aquí, en nuestro país, para nuestros compatriotas. En palabras sencillas, podremos crecer más rápido y entonces concentrar mejor nuestra atención para beneficiar a quienes menos tienen" (Salinas de Gortari, citado en Secretaría de Comercio y Fomento Industrial (SECOFI), 1992, pág. 1). ${ }^{2}$ El modelo INFORUm (1991, VII-A-1) fue uno de los pocos en que se intentó realizar estimaciones a nivel regional y sectorial en México. Sobre la base de la eliminación de los aranceles (hipótesis 1) y la eliminación de los aranceles y de las barreras no arancelarias (hipótesis 2), se calculó que en 1989 las exportaciones estadounidenses a México habrían aumentado más en los sectores de la agricultura, las computadoras y los automóviles, mientras que las importaciones de prendas de vestir y televisores lo habrían hecho en menor medida. Desde este punto de vista, las exportaciones estadounidenses a México habrían aumentado un $27 \%$ en la segunda hipótesis y las importaciones de México un 7\% en el período 1989-2000. En el mismo modelo se asumían efectos negativos en el sector agrícola y efectos positivos en los sectores manufactureros en general en el período 1989-2000. 3 "El empleo estadounidense se ha trasladado al otro lado de la frontera para pagar, sobre todo a mujeres jóvenes, mucho menos de un dólar por hora ... Las maquilas constituyen un modelo de desarrollo económico ligado a los salarios más bajos del mundo para atraer inversiones de corporaciones multinacionales que producen para mercados externos, no internos. Los trabajadores con bajos salarios no pueden comprar productos "competitivos a nivel internacional". No hemos visto que los estándares de vida de los trabajadores mexicanos hayan mejorado gracias a esta estrategia de desarrollo económico" (Steve Beckman, United Auto Workers Association, citado en Comisión de Comercio Internacional de los Estados Unidos, 1990, págs. 1-23).
} 
empleo, creación de empresas y competitividad como consecuencia del TLCAN (Donahue, 1991). Se plantearon en forma explícita problemas como la debilidad de las instituciones regionales, incluso en comparación con el proceso de integración en la Unión Europea (Baer, 1991; Donahue, 1991; Piore, 1991; Shelburne, 1991) ${ }^{4}$. En general, de acuerdo con las estimaciones relativas a los sectores manufactureros, el comercio intraindustrial aumentaría en forma considerable en la región. De acuerdo con la Oficina de Presupuesto del Congreso (Сво), el TLCAN estimularía las exportaciones de automóviles y sus repuestos y piezas hacia México, mientras que las importaciones aumentarían a un ritmo menor, de modo que se produciría un superávit o el déficit se reduciría. La CBO previó además el incremento en ambas direcciones del comercio de la industria textil y de prendas de vestir entre los Estados Unidos de América y México (сво, 1993). No obstante, algunos analistas de la industria expresaron preocupación con respecto a China en una

\footnotetext{
${ }^{4}$ Los representantes de varias cámaras de industria, como la Cámara Nacional de la Industria de Transformación (CANACINTRA), manifestaron su escepticismo sobre las posibilidades de cambios macroeconómicos desde 1994 y respecto del TLCAN: "Consideramos que no basta estabilizar los signos vitales de la economía. Tampoco es suficiente modificar las bases para el desarrollo nacional, ni replantear nuestra inserción en las corrientes internacionales de bienes y capitales, o adecuar el marco regulatorio, si todo ello no es complementado por una profunda e intensa reestructuración de las actividades y empresas que integran el tejido económico del país" (CANACINTRA, 1994, pág. 16; véase también Caballero Urdiales, 1991, pág. 65 y ss.).
}

etapa temprana del debate sobre los efectos del TLCAN en la cadena de valor agregado hilo-textiles-confección. Si bien las exportaciones chinas (y de otros países asiáticos) eran más competitivas que las mexicanas con relación al mercado de importación estadounidense, se esperaba que el acuerdo incrementara la participación mexicana de modo que ambos países pudieran unir fuerzas para hacer frente a los desafíos externos.

Lande (1991, pág. 244) sostuvo que las relaciones cambiarias continuarían favoreciendo a las operaciones intensivas en mano de obra en México y el Caribe respecto de las fuentes tradicionales del Lejano Oriente. Ese mismo analista afirmó que el TLCAN sería muy apreciado en los Estados Unidos de América: si el acceso de México aumenta mientras se reducen las exportaciones del Lejano Oriente, las probabilidades de éxito serán mayores. Se considera que las importaciones de la industria nacional mexicana representan una amenaza menor para los productores estadounidenses que las importaciones del Lejano Oriente o de instalaciones controladas por empresas de aquel lugar en terceros países. Los productores de esa región no comercializan sus productos a través de los fabricantes de prendas de vestir estadounidenses, sino que con frecuencia venden directamente a los comerciantes al por menor o a contratistas en los Estados Unidos de América. Por el contrario, los productores mexicanos son más propensos a utilizar los canales de distribución estadounidenses normales, incluidas las empresas de prendas de vestir estadounidenses (Lande, 1991, pág. 243).

\section{III}

\section{Análisis: China se cuela en la fiesta del TLCAN}

En esta sección se analiza la penetración de los productos chinos en los mercados estadounidense y mexicano, haciendo hincapié en este último mercado. Desde su ingreso a la OMC en 2001 y hasta 2009, se observa que China está aventajando a México en el mercado estadounidense y comenzando a competir con los Estados Unidos de América en el mercado mexicano. Es interesante notar que mientras la participación estadounidense en 53 sectores del mercado mexicano disminuye, la participación china crece, aparentemente permitiendo a México incrementar su eficiencia y volverse más competitivo en los mercados estadounidenses. Sin embargo, la participación mexicana en esos 53 sectores del mercado estadounidense, que representan el $49 \%$ de las exportaciones de México a dicho mercado, también se está aminorando. En los estudios de caso que se presentan a continuación se examinan esas tendencias de la economía mexicana con mayor detalle.

Esta sección se divide a su vez en dos subsecciones. En la primera de ellas se resumen las tendencias comerciales entre los Estados Unidos de América, México y China desde una perspectiva histórica. En tanto que en la segunda subsección se analiza la competencia entre México y China en los mercados de importación estadounidenses, y se examina la competencia entre los Estados Unidos de América y 
China en los mercados mexicanos. Por último, se estudia un subconjunto de 53 sectores del mercado mexicano en que los Estados Unidos de América están perdiendo participación en favor de China y en los que México, a su vez, también está perdiendo participación en el mercado estadounidense.

\section{TLCAN: condiciones y evolución}

China se está convirtiendo en un importante socio comercial, tanto para México como para los Estados Unidos de América. Mientras que en 1995 no se encontraba entre los primeros cinco socios comerciales de ninguno de los dos países, en 2009 se había convertido en el segundo mayor socio comercial de ambos. En el cuadro 1 se muestra el notable crecimiento de China en los mercados de importación estadounidense y mexicano desde su ingreso a la omc en 2001.

Como se puede apreciar en el cuadro 1, en 2005 China superó a México y se convirtió en el segundo mayor socio comercial de los Estados Unidos de América, posición que mantiene desde entonces.

A medida que el mercado estadounidense se ha vuelto más abierto, tanto México como China han ganado terreno. Ambos países tienen perfiles exportadores muy similares (Blázquez-Lidoy, Rodríguez y Santiso, 2006;
Feenstra, 2007) y compiten desde hace ya algún tiempo en el mercado estadounidense con manufacturas que no requieren mano de obra especializada. En el gráfico 1 se observa que la participación de los productos mexicanos en el mercado estadounidense fue aumentando hasta alcanzar el 11,6\% en 2002 (apenas un año después de que China ingresara en la OMC), mientras que la participación de China se incrementó repentinamente al 12,1\% en 2003 y continuó acrecentándose desde entonces. En 2010 los productos chinos representaban el 19,1\% de las importaciones estadounidenses, mientras que la cuota de mercado de México era del 12,1\%.

Si bien de modo menos drástico, los Estados Unidos de América también están perdiendo terreno en los mercados mexicanos a medida que crece la participación de China. En los primeros cinco años posteriores al TLCAN, la participación estadounidense en los mercados de importación mexicanos bordeaba el $75 \%$, cifra que se redujo al $48 \%$ en 2009. Aunque la participación china se ha incrementado, todavía representa una parte relativamente pequeña de las importaciones mexicanas. Como se muestra en el gráfico 2, mientras China representaba menos del $0,75 \%$ del mercado mexicano en 2000, esa cifra alcanzó al 15,13\% en 2010. Según se verá más adelante, en algunos sectores esa tendencia es aún más impresionante.

Principales socios comerciales de México y los Estados Unidos de América, 1993-2009

(Participación en el comercio total)

\begin{tabular}{|c|c|c|c|c|c|}
\hline \multicolumn{6}{|c|}{ México } \\
\hline & 1 & 2 & 3 & 4 & 5 \\
\hline 1994 & Estados Unidos de América & Japón & Alemania & Canadá & España \\
\hline 2000 & Estados Unidos de América & Canadá & Japón & Alemania & República de Corea \\
\hline 2003 & Estados Unidos de América & China & Japón & Alemania & Canadá \\
\hline 2009 & Estados Unidos de América & China & Canadá & Japón & Alemania \\
\hline \multicolumn{6}{|c|}{ Estados Unidos de América } \\
\hline & 1 & 2 & 3 & 4 & 5 \\
\hline & & & & Reino Unido de Gran & \\
\hline $\begin{array}{l}1993 \\
1999\end{array}$ & Canadá & $\begin{array}{l}\text { Japón } \\
\text { México }\end{array}$ & $\begin{array}{l}\text { México } \\
\text { Janón }\end{array}$ & Bretaña e Irlanda del Norte & Alemania \\
\hline 2003 & Canadá & México & China & Japón & Alemania \\
\hline 2009 & Canadá & China & México & Japón & Alemania \\
\hline
\end{tabular}

Fuente: elaborado por los autores a partir de la Base de datos estadísticos sobre el comercio de mercaderías (COMTRADE). 
GRÁFICO 1

Estados Unidos de América: participación en las importaciones totales, 1991-2010

(En porcentajes)

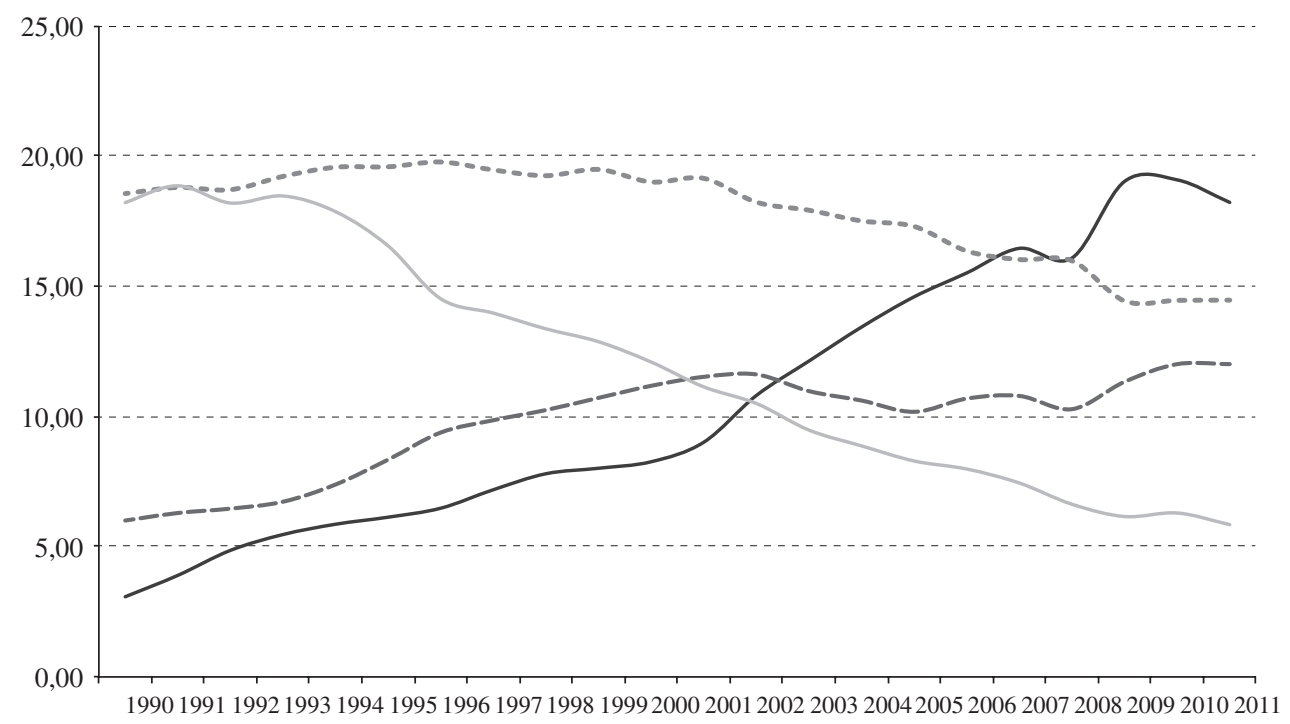

—China -.--Canadá ---México —Japón

Fuente: elaborado por los autores sobre la base de Comisión de Comercio Internacional de los Estados Unidos, 2011.

GRÁFICO 2

México: importaciones desde China y los Estados Unidos de América, 1995-2010 (Participación porcentual en el total)

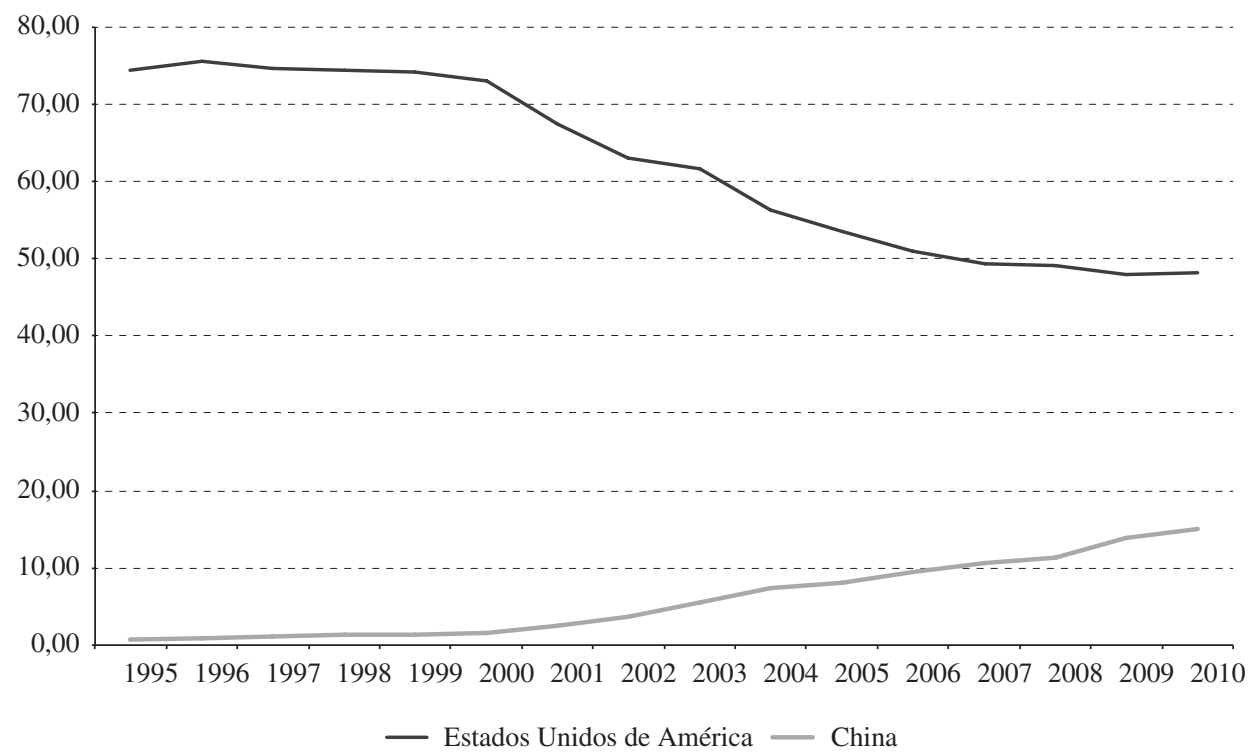

Fuente: elaborado por los autores sobre la base de World Trade Atlas, 2011. 
En el cuadro 2 se detallan los 20 principales productos de exportación de México a los Estados Unidos de América en 2000 y los 20 principales productos de exportación de los Estados Unidos a México en ese mismo año. Esa fecha sirve como parámetro antes de que China ingresara a la OMC y coincide con un momento de auge en el comercio entre ambos países. En tanto que la participación china en el mercado estadounidense con respecto a esos 20 productos pasó de un 6,22\% en 2000 al 19,42\% en 2009, la participación mexicana disminuyó del $16,61 \%$ al $16,06 \%$ en ese mismo período. Por otra parte, la participación estadounidense en el mercado mexicano con respecto a esos 20 productos se redujo del $72 \%$ en 2000 al 41,54\% en 2009, a la vez que la de China aumentó notablemente de un 1,09\% al 17,83\% en igual período

\section{2. ¿Constituye China una "amenaza" para el comercio norteamericano?}

¿Es posible determinar la medida en que las empresas chinas están aventajando a sus pares mexicanas y estadounidenses a un nivel sectorial más específico? Para este análisis se recurrió a una metodología consolidada establecida por Lall y Weiss (2005). Estos autores estudian cómo ha evolucionado la participación de las

México y Estados Unidos de América: principales exportaciones, 2000

\begin{tabular}{|c|c|c|c|c|}
\hline & & $\begin{array}{l}20 \text { principales productos de exportación de los } \\
\text { Estados Unidos de América a México, } 2000\end{array}$ & & $\begin{array}{l}20 \text { principales productos de exportación de México a } \\
\text { los Estados Unidos de América, } 2000\end{array}$ \\
\hline 1 & S2-776 & $\begin{array}{l}\text { Dispositivos termoiónicos, microcircuitos, } \\
\text { transistores, válvulas y otros }\end{array}$ & S2-781 & $\begin{array}{l}\text { Vehículos automotores para pasajeros (excluidos } \\
\text { los autobuses) }\end{array}$ \\
\hline 2 & S2-784 & $\begin{array}{l}\text { Partes, piezas y accesorios de vehículos } \\
\text { automotores n.e.p. }\end{array}$ & S2-333 & $\begin{array}{l}\text { Aceites de petróleo y aceites obtenidos de } \\
\text { minerales bituminosos, crudos }\end{array}$ \\
\hline 3 & S2-772 & $\begin{array}{l}\text { Aparatos eléctricos para abrir y cerrar circuitos } \\
\text { eléctricos }\end{array}$ & S2-764 & $\begin{array}{l}\text { Equipos de telecomunicaciones n.e.p.; partes, } \\
\text { piezas y accesorios n.e.p. }\end{array}$ \\
\hline 4 & S2-699 & Manufacturas de metales comunes n.e.p. & S2-752 & $\begin{array}{l}\text { Máquinas de procesamiento automático de datos y } \\
\text { sus unidades }\end{array}$ \\
\hline 5 & S2-893 & Artículos de materiales plásticos n.e.p. & S2-931 & $\begin{array}{l}\text { Operaciones y mercancías especiales no } \\
\text { clasificadas según su naturaleza }\end{array}$ \\
\hline 6 & S2-778 & Máquinas y aparatos eléctricos n.e.p. & S2-773 & Equipos de distribución de electricidad \\
\hline 7 & S2-764 & $\begin{array}{l}\text { Equipos de telecomunicaciones n.e.p.; partes, } \\
\text { piezas y accesorios n.e.p. }\end{array}$ & S2-782 & $\begin{array}{l}\text { Vehículos automotores para el transporte de } \\
\text { mercancías y vehículos automotores para usos } \\
\text { especiales }\end{array}$ \\
\hline 8 & S2-773 & Equipos de distribución de electricidad & S2-784 & $\begin{array}{l}\text { Partes, piezas y accesorios de vehículos } \\
\text { automotores n.e.p. }\end{array}$ \\
\hline 9 & S2-583 & Productos de polimerización y copolimerización & S2-761 & Receptores de televisión \\
\hline 10 & S2-713 & $\begin{array}{l}\text { Motores de combustión interna de émbolo y sus } \\
\text { partes y piezas, n.e.p. }\end{array}$ & S2-772 & $\begin{array}{l}\text { Aparatos eléctricos para abrir y cerrar circuitos } \\
\text { eléctricos }\end{array}$ \\
\hline 11 & S2-781 & $\begin{array}{l}\text { Vehículos automotores para pasajeros (excluidos } \\
\text { los autobuses) }\end{array}$ & S2-821 & Muebles y sus partes \\
\hline 12 & S2-334 & Productos derivados del petróleo, refinados & S2-778 & Máquinas y aparatos eléctricos n.e.p. \\
\hline 13 & S2-749 & $\begin{array}{l}\text { Partes, piezas y accesorios no eléctricos para } \\
\text { maquinaria, n.e.p. }\end{array}$ & S2-713 & $\begin{array}{l}\text { Motores de combustión interna de émbolo y sus } \\
\text { partes y piezas, n.e.p. }\end{array}$ \\
\hline 14 & S2-752 & $\begin{array}{l}\text { Máquinas de procesamiento automático de datos y } \\
\text { sus unidades }\end{array}$ & S2-842 & $\begin{array}{l}\text { Ropa de calle para hombres y niños, de tejidos que } \\
\text { no sean de punto o ganchillo }\end{array}$ \\
\hline 15 & S2-874 & $\begin{array}{l}\text { Instrumentos de medición, verificación, análisis y } \\
\text { control n.e.p., partes y piezas }\end{array}$ & S2-759 & $\begin{array}{l}\text { Partes, n.e.p. y accesorios para máquinas de las } \\
\text { partidas } 751 \text { ó } 752\end{array}$ \\
\hline 16 & S2-642 & $\begin{array}{l}\text { Papel y cartón precortados y artículos de papel o } \\
\text { cartón }\end{array}$ & S2-843 & $\begin{array}{l}\text { Ropa de calle para mujeres, niñas y bebés, de } \\
\text { tejidos que no sean de punto o ganchillo }\end{array}$ \\
\hline 17 & S2-771 & $\begin{array}{l}\text { Máquinas de energía eléctrica, y sus partes y } \\
\text { piezas, n.e.p. }\end{array}$ & S2-771 & $\begin{array}{l}\text { Máquinas de energía eléctrica, y sus partes y } \\
\text { piezas, n.e.p. }\end{array}$ \\
\hline 18 & S2-759 & $\begin{array}{l}\text { Partes, n.e.p. y accesorios para máquinas de las } \\
\text { partidas } 751 \text { o } 752\end{array}$ & S2-874 & $\begin{array}{l}\text { Instrumentos de medición, verificación, análisis y } \\
\text { control n.e.p., partes y piezas }\end{array}$ \\
\hline 19 & S2-728 & $\begin{array}{l}\text { Otras máquinas y equipos para industrias } \\
\text { especializadas; partes y piezas n.e.p. }\end{array}$ & S2-716 & $\begin{array}{l}\text { Aparatos eléctricos rotativos y sus partes y piezas, } \\
\text { n.e.p. }\end{array}$ \\
\hline 20 & S2-931 & $\begin{array}{l}\text { Operaciones y mercancías especiales no } \\
\text { clasificadas según su naturaleza }\end{array}$ & S2-762 & Radiorreceptores \\
\hline
\end{tabular}

Fuente: elaborado por los autores a partir de la Base de datos estadísticos sobre el comercio de mercaderías (COMTRADE).

n.e.p.: no especificado en otra parte. 
exportaciones de China y América Latina y el Caribe al resto del mundo y al mercado estadounidense, y buscan las pruebas de una mayor competencia china en segmentos que registran un aumento de la penetración de sus exportaciones a medida que decrece la penetración de los productos de América Latina y el Caribe.

Como se aprecia en el cuadro 3, Lall y Weiss (2005) definen varias categorías de interacción competitiva entre China y otros países en los mercados de exportación. Cuando la participación de China en el mercado estadounidense aumenta a medida que la participación de América Latina y el Caribe disminuye, los autores consideran que la región sufre una "amenaza directa" de China. En forma análoga, cuando la participación de China y de América Latina y el Caribe se incrementa, pero la primera lo hace con mayor rapidez, se trataría de un caso de "amenaza parcial" de China.

En el cuadro 4 se presentan los resultados obtenidos con la metodología de Lall y Weiss (2005). Para realizar estos cálculos se analizó el comercio entre 2000 (año anterior al ingreso de China en la OMC) y 2009. El análisis comprende 118 sectores que cubren todo el comercio y se desagrega a nivel de tres dígitos utilizando el sistema de clasificación de la Base de datos estadísticos sobre el comercio de mercaderías (COMTRADE) con respecto a las economías estadounidense y mexicana. Se calculó la participación de mercado en cada sector en 2000 y 2009 y su variación en puntos porcentuales en el período de referencia. Una vez más, cuando la participación de los Estados Unidos de América o de México merma en un

\section{Matriz de interacciones competitivas entre China y otros países} en los mercados de exportación

Participación de China en los mercados de exportación

\begin{tabular}{|c|c|c|c|}
\hline & & Aumenta & Disminuye \\
\hline \multirow{6}{*}{$\begin{array}{l}\text { Participación } \\
\text { de otros } \\
\text { países en los } \\
\text { mercados de } \\
\text { exportación }\end{array}$} & \multirow{4}{*}{ Aumenta } & A. No hay amenaza & C. Amenaza inversa \\
\hline & & $\begin{array}{l}\text { La participación de ambos países crece, pero el } \\
\text { incremento del otro país es mayor que el de China }\end{array}$ & \multirow[t]{3}{*}{$\begin{array}{l}\text { China no constituye una amenaza competitiva } \\
\text { para otros países, sino que estos representan una } \\
\text { amenaza para China }\end{array}$} \\
\hline & & B. Amenaza parcial & \\
\hline & & $\begin{array}{l}\text { La participación de ambos países se acrecienta, } \\
\text { pero el incremento de China es más rápido que el } \\
\text { del otro país }\end{array}$ & \\
\hline & \multirow[b]{2}{*}{ Disminuye } & D. Amenaza directa & E. Retirada de ambos países: no hay amenaza \\
\hline & & $\begin{array}{l}\text { La participación de China aumenta mientras que } \\
\text { la del otro país se aminora; esto puede indicar } \\
\text { una relación causal a menos que el otro país ya } \\
\text { perdiera participación antes del ingreso de China }\end{array}$ & $\begin{array}{l}\text { Ambas partes pierden participación en los } \\
\text { mercados de exportación en favor de otros } \\
\text { competidores }\end{array}$ \\
\hline
\end{tabular}

Fuente: Sanjaya Lall y John Weiss, "China's competitive threat to Latin America: an analysis for 1990-2002", Oxford Development Studies, vol. 33, $\mathrm{N}^{\circ}$ 2, Taylor \& Francis, 2005.

CUADRO 4

"Amenaza china" en los mercados mexicano y estadounidense (En porcentajes)

\begin{tabular}{llccc}
\hline & & Directa & Parcial & Total \\
\hline $\begin{array}{l}\text { Estados Unidos } \\
\text { de América }\end{array}$ & Porcentaje de exportaciones de manufacturas a México & 96 & 0 & 96 \\
\hline \multirow{2}{*}{ México } & Porcentaje de exportaciones totales a México & 62 & 0 & 62 \\
& $\begin{array}{l}\text { Porcentaje de exportaciones de manufacturas a los Estados Unidos } \\
\text { de América }\end{array}$ & 52 & 29 & 81 \\
\hline
\end{tabular}

Fuente: elaborado por los autores a partir de la Base de datos estadísticos sobre el comercio de mercaderías (COMTRADE), 2011; y Sanjaya Lall y John Weiss, "China's competitive threat to Latin America: an analysis for 1990-2002", Oxford Development Studies, vol. 33, N 2 , Taylor \& Francis, 2005. 
sector del mercado en que la participación china aumenta, se habla de "amenaza directa", y cuando la participación de ambos países se incrementa, pero a un ritmo más lento que la de China, se habla de "amenaza parcial".

Del cuadro 4 surge que el $96 \%$ de las exportaciones de manufacturas estadounidenses a México, que representan el $62 \%$ de las exportaciones estadounidenses totales a ese país, están bajo la amenaza de China. Cabe destacar que en ninguno de esos casos se trata de amenazas parciales, sino de amenazas directas. Por otra parte, el $81 \%$ de las exportaciones de manufacturas mexicanas y el $56 \%$ de las exportaciones totales de ese país están bajo amenaza de China en el mercado de importaciones estadounidense. En el caso de las manufacturas mexicanas, el 52\% de las exportaciones de ese país a los Estados Unidos de América tienen una amenaza directa y el $29 \%$ una amenaza parcial. El único sector en que México no está bajo la amenaza de China o está ganando participación en el mercado con respecto a ese país es el de los automóviles, camiones y sus partes y piezas. Esto se debe a que esos artículos son físicamente pesados para el transporte desde China y a que el sector automotor norteamericano goza de protección en el marco del TLCAN (Gallagher, MorenoBrid y Porzecanski, 2008). Por último, China constituye una amenaza directa para el $36 \%$ de las exportaciones mexicanas totales y una amenaza parcial para el $20 \%$. A diferencia de México, China no exporta petróleo y otros productos primarios a los Estados Unidos de América, y eso explica por qué su participación en las exportaciones totales no es tan significativa.

En el cuadro 5 se detallan 53 sectores que se definen como bajo "triple amenaza". En esos sectores, que representan el $49 \%$ de las exportaciones mexicanas, los Estados Unidos de América están perdiendo participación en favor de China en el mercado mexicano y México está perdiendo participación en favor de China en el mercado estadounidense. En primer lugar, se examina la posición de los Estados Unidos de América y China en el mercado mexicano. En los 53 sectores analizados, la participación estadounidense en las exportaciones mexicanas de cada sector correspondía a un promedio del $69 \%$ en 2000. En 2009 ese porcentaje había descendido a solo el $43 \%$, es decir, registró una variación de 26 puntos porcentuales en solo nueve años. Por ejemplo, mientras que en 2000 los Estados Unidos de América representaban el $68 \%$ del mercado mexicano de fibras sintéticas y China el 0,1\%, en 2009 la participación estadounidense había disminuido 20 puntos porcentuales, en tanto que la de China había aumentado casi 14 puntos porcentuales. Asimismo, mientras que en 2000 los Estados Unidos de América abastecieron a México con el 60,8\% de sus importaciones de computadoras y máquinas de oficina y el $70 \%$ de los dispositivos periféricos para esas máquinas, en 2009 esas cifras se contrajeron 51 puntos porcentuales y 60 puntos porcentuales, respectivamente. En 2009 la participación estadounidense en cada uno de esos sectores del mercado de importaciones mexicano era de apenas un $10 \%$. Por el contrario, mientras que la participación china en el mercado de importaciones de máquinas de oficina y de partes y piezas ascendía en México al $13 \%$ y al 5\%, respectivamente en 2000, nueve años después había alcanzado al $48 \%$ y al 58\%, respectivamente. Si bien en 2000 los Estados Unidos de América dominaban el $60 \%$ del mercado mexicano de las telecomunicaciones, perdieron 44 puntos porcentuales hasta llegar a apenas el 16\% del mercado en 2009. Mientras que en 2000 ese país proporcionaba el $90 \%$ de las importaciones mexicanas de manufacturas de metales comunes, esa cifra descendió 30 puntos porcentuales en 2009 cuando China pasó del $0 \%$ al $15 \%$.

La pérdida de participación estadounidense en el mercado mexicano en favor de China indicaría que las empresas orientadas a las exportaciones que operan en México tendrían la oportunidad de incrementar su eficiencia y productividad. Se presume que los Estados Unidos de América están perdiendo terreno porque las importaciones chinas son más baratas que sus equivalentes estadounidenses. En la medida en que las exportaciones chinas a México representan insumos para las empresas mexicanas, estas últimas deberían poder exportar a un precio más competitivo (Lederman, Olarreaga y Rubiano, 2008). Sin embargo, en esos mismos 53 sectores de mercado en que los Estados Unidos de América están perdiendo participación en favor de China, México también está perdiendo participación en favor de China en el mercado estadounidense. En promedio, México había conquistado el 14\% del mercado de importación estadounidense en esos sectores en 2000, pero esa participación se redujo al $9 \%$ en 2009. Para volver al ejemplo de las fibras sintéticas, mientras que en el año 2000 México representaba el 15\% del mercado de importación de los Estados Unidos de América, ese porcentaje disminuyó 14 puntos porcentuales llegando a solo un $1 \%$ en 2009. En tanto que en el mismo año México suministró a ese país el $9 \%$ de sus importaciones de máquinas de oficina o computadoras y el $11 \%$ de los dispositivos periféricos para esas máquinas, en 2009 esas cifras se contrajeron 9 puntos porcentuales y 5 puntos porcentuales, respectivamente, hasta alcanzar alrededor de un $1 \%$ y un $2 \%$, respectivamente. En el caso de las telecomunicaciones, México también está perdiendo su cuota de mercado en los Estados Unidos de América. 
CUADRO 5

La "triple amenaza"

(En porcentajes)

\begin{tabular}{|c|c|c|c|c|}
\hline & Artículos & $\begin{array}{l}\text { Variación en las } \\
\text { exportaciones de los } \\
\text { Estados Unidos de } \\
\text { América a México } \\
\text { (2000-2009) }\end{array}$ & $\begin{array}{c}\text { Variación en las } \\
\text { exportaciones de } \\
\text { China a México } \\
\text { (2000-2009) }\end{array}$ & $\begin{array}{l}\text { Variación en las } \\
\text { exportaciones de } \\
\text { México a los Estados } \\
\text { Unidos de América } \\
\text { (2000-2009) }\end{array}$ \\
\hline 1 & Fibras sintéticas adecuadas para el hilado & $-20,5$ & 13,4 & $-14,1$ \\
\hline 2 & $\begin{array}{l}\text { Otras fibras manufacturadas adecuadas para el hilado y } \\
\text { desperdicios de fibras manufacturadas }\end{array}$ & $-2,6$ & 8,0 & $-7,1$ \\
\hline 3 & Alcoholes, fenoles y otros, y sus derivados & $-11,1$ & 1,4 & $-1,2$ \\
\hline 4 & Jabón y preparados para limpiar y pulir & $-8,8$ & 0,9 & $-5,9$ \\
\hline 5 & Abonos, manufacturados & $-7,0$ & 5,4 & $-0,04$ \\
\hline 6 & Celulosa regenerada, derivados de la celulosa, fibra vulcanizada & $-19,0$ & 3,2 & $-0,3$ \\
\hline 7 & Pesticidas, desinfectantes & $-1,0$ & 2,8 & $-3,7$ \\
\hline 8 & Productos químicos diversos, n.e.p. & $-11,0$ & 2,5 & $-0,3$ \\
\hline 9 & Manufacturas de cuero natural o sintético, n.e.p., y otros & $-36,9$ & 8,4 & $-7,6$ \\
\hline 10 & $\begin{array}{l}\text { Pieles finas curtidas o adobadas; piezas o recortes de pieles } \\
\text { curtidas o adobadas }\end{array}$ & $-45,8$ & 1,5 & $-0,6$ \\
\hline 11 & Tejidos de algodón (excepto tejidos estrechos o especiales) & $-21,3$ & 11,2 & $-6,0$ \\
\hline 12 & $\begin{array}{l}\text { Tejidos de materias textiles manufacturadas (excepto tejidos } \\
\text { estrechos o especiales) }\end{array}$ & $-5,7$ & 9,0 & $-1,0$ \\
\hline 13 & $\begin{array}{l}\text { Tejidos de punto o ganchillo (incluso tejidos de punto tubulares } \\
\text { y otros) }\end{array}$ & $-13,1$ & 15,8 & $-4,0$ \\
\hline 14 & $\begin{array}{l}\text { Tules, encajes, bordados, cintas, pasamanería y otras } \\
\text { confecciones pequeñas }\end{array}$ & $-30,0$ & 9,4 & $-4,6$ \\
\hline 15 & $\begin{array}{l}\text { Artículos confeccionados total o parcialmente de materias } \\
\text { textiles, n.e.p. }\end{array}$ & $-44,3$ & 25,9 & $-8,0$ \\
\hline 16 & Recubrimientos para pisos, y otros & $-19,7$ & 3,2 & $-0,4$ \\
\hline 17 & Artículos de cerámica & $-9,1$ & 46,7 & $-1,9$ \\
\hline 18 & Productos universales, planchas y hojas de hierro o acero & $-13,5$ & 1,9 & $-1,9$ \\
\hline 19 & Tubos, caños y accesorios de hierro o acero & $-12,5$ & 11,3 & $-1,7$ \\
\hline 20 & $\begin{array}{l}\text { Clavos, tornillos, tuercas, pernos, remaches y artículos análogos, } \\
\text { de hierro, acero o cobre }\end{array}$ & $-28,6$ & 8,9 & $-0,9$ \\
\hline 21 & Cuchillería & $-19,4$ & 11,5 & $-0,9$ \\
\hline 22 & Enseres domésticos de metales comunes, n.e.p. & $-26,8$ & 28,5 & $-9,8$ \\
\hline 23 & Manufacturas de metales comunes, n.e.p. & $-29,6$ & 14,9 & $-1,5$ \\
\hline 24 & $\begin{array}{l}\text { Calderas generadoras de vapor de agua y aparatos auxiliares, y } \\
\text { sus partes y piezas, n.e.p. }\end{array}$ & $-5,1$ & 9,0 & $-0,4$ \\
\hline 25 & Aparatos eléctricos rotativos y sus partes y piezas, n.e.p. & $-16,2$ & 15,6 & $-12,2$ \\
\hline 26 & $\begin{array}{l}\text { Maquinaria y equipo de ingeniería civil y para contratistas, y sus } \\
\text { partes y piezas, n.e.p. }\end{array}$ & $-12,3$ & 2,5 & $-0,2$ \\
\hline 27 & $\begin{array}{l}\text { Máquinas para elaborar alimentos (excepto las de uso doméstico) } \\
\text { y sus partes y piezas, n.e.p. }\end{array}$ & $-11,3$ & 1,9 & $-1,2$ \\
\hline 28 & Partes y accesorios no eléctricos de máquinas, n.e.p. & $-22,4$ & 8,3 & $-2,7$ \\
\hline 29 & Máquinas de oficina & $-51,1$ & 35,0 & $-8,1$ \\
\hline 30 & $\begin{array}{l}\text { Partes, n.e.p. y accesorios para máquinas de las partidas } \\
751 \text { o } 752\end{array}$ & $-60,3$ & 53,4 & $-4,8$ \\
\hline 31 & Receptores de televisión & $-28,4$ & 27,2 & $-11,3$ \\
\hline 32 & Radiorreceptores & $-2,8$ & 8,0 & $-9,1$ \\
\hline 33 & Gramófonos, dictáfonos y otros grabadores de sonido & $-42,2$ & 53,4 & $-4,5$ \\
\hline 34 & $\begin{array}{l}\text { Equipos de telecomunicaciones n.e.p.; partes, piezas y accesorios } \\
\text { n.e.p. }\end{array}$ & $-43,6$ & 37,0 & $-2,5$ \\
\hline 35 & Aparatos de electricidad y sus partes y piezas, n.e.p. & $-51,5$ & 36,7 & $-7,0$ \\
\hline 36 & Equipos de distribución de electricidad & $-27,6$ & 15,7 & $-16,8$ \\
\hline
\end{tabular}




\begin{tabular}{|c|c|c|c|c|}
\hline & Artículos & $\begin{array}{l}\text { Variación en las } \\
\text { exportaciones de los } \\
\text { Estados Unidos de } \\
\text { América a México } \\
\text { (2000-2009) }\end{array}$ & $\begin{array}{c}\text { Variación en las } \\
\text { exportaciones de } \\
\text { China a México } \\
\text { (2000-2009) }\end{array}$ & $\begin{array}{l}\text { Variación en las } \\
\text { exportaciones de } \\
\text { México a los Estados } \\
\text { Unidos de América } \\
\text { (2000-2009) }\end{array}$ \\
\hline 37 & Aparatos eléctricos de diagnóstico y aparatos radiológicos & $-16,2$ & 5,1 & $-1,4$ \\
\hline 38 & Vehículos automotores para pasajeros (excluidos los autobuses) & $-26,8$ & 0,3 & $-2,0$ \\
\hline 39 & Remolques y otros vehículos no motorizados, n.e.p. & $-9,0$ & 6,7 & $-2,0$ \\
\hline 40 & Vehículos para ferrocarriles y equipo conexo & $-31,3$ & 7,2 & $-16,4$ \\
\hline 41 & Muebles y sus partes & $-32,4$ & 18,3 & $-4,5$ \\
\hline 42 & $\begin{array}{l}\text { Artículos de viaje, bolsos de mano y otros artículos análogos de } \\
\text { cuero, plástico, tela y otros materiales }\end{array}$ & $-22,6$ & 20,6 & $-2,4$ \\
\hline 43 & $\begin{array}{l}\text { Ropa de calle para hombres y niños, de tejidos que no sean de } \\
\text { punto o ganchillo }\end{array}$ & $-47,9$ & 8,7 & $-5,9$ \\
\hline 45 & $\begin{array}{l}\text { Ropa de calle de tejidos de punto o ganchillo, no elastizada ni } \\
\text { engomada }\end{array}$ & $-61,4$ & 5,0 & $-7,6$ \\
\hline 46 & Ropa interior de tejidos de punto o ganchillo & $-72,7$ & 0,5 & $-13,1$ \\
\hline 47 & Accesorios de vestir de tela, n.e.p. & $-45,6$ & 14,1 & $-5,7$ \\
\hline 48 & $\begin{array}{l}\text { Prendas y accesorios de vestir que no sean de materias textiles; } \\
\text { sombreros y otros artículos de tocado }\end{array}$ & $-57,2$ & 38,1 & $-0,7$ \\
\hline 49 & Calzado & $-8,2$ & 9,5 & $-0,7$ \\
\hline 50 & Medidores y contadores, n.e.p. & $-13,7$ & 6,4 & $-5,1$ \\
\hline 51 & $\begin{array}{l}\text { Instrumentos de medición, verificación, análisis y control n.e.p., } \\
\text { partes y piezas }\end{array}$ & $-26,1$ & 5,7 & $-4,1$ \\
\hline 52 & Materiales fotográficos y cinematográficos & $-4,2$ & 1,0 & $-3,6$ \\
\hline 53 & Cochecitos para niños, juguetes, juegos y artículos de deporte & $-26,7$ & 34,1 & $-1,5$ \\
\hline
\end{tabular}

Fuente: elaborado por los autores a partir de la Base de datos estadísticos sobre el comercio de mercaderías (COMTRADE), 2011.

n.e.p.: no especificado en otra parte.

\section{IV}

\section{Estudios de caso}

El TLCAN ha pasado por al menos dos etapas desde su implementación: de 1994 a 2000, cuando se profundizó la integración en términos de comercio e inversiones, y de 2001 a 2010, cuando la mayoría de los procesos previos se invirtieron ${ }^{5}$. En el cuadro 6 se explican esas tendencias y los profundos cambios en el comercio de México en la última década: el comercio con los Estados

\footnotetext{
${ }^{5}$ Véase un análisis detallado del comercio intraindustrial entre México, China y los Estados Unidos de América en Cárdenas Castro y Dussel Peters (2011). El comercio intraindustrial alcanzó su máximo nivel en 2000 y ha disminuido en forma constante desde entonces.
}

Unidos de América se redujo del 81,03\% de su comercio total en 1999 al $63,95 \%$ en 2010 , sobre todo como consecuencia de la disminución de las importaciones de México (del 74,15\% al 48,10\% de las importaciones totales en el mismo período), aunque su participación en las exportaciones a los Estados Unidos de América también descendió casi un 9\%.

Para comprender estas tendencias, se analizan a continuación dos cadenas de valor agregado específicas en México en el contexto del TLCAN y las relaciones con los Estados Unidos de América. Como se indicó en la sección anterior, en ambos casos se esperaba un desempeño destacado en el contexto del TLCAN. 
CUADRO 6

México: principales estructuras comerciales, 1993-2010

(Participación en el total)

\begin{tabular}{|c|c|c|c|c|c|c|}
\hline & Total & $\begin{array}{c}\text { Estados Unidos de } \\
\text { América }\end{array}$ & Unión Europea & $\begin{array}{c}\text { Asia } \\
\text { (incluye China) }\end{array}$ & Otros & China \\
\hline \multicolumn{7}{|c|}{ Exportaciones } \\
\hline 1993 & 100,00 & 82,7 & 5,21 & 2,6 & 9,49 & 0,09 \\
\hline 1994 & 100,00 & 84,78 & 4,72 & 2,54 & 7,96 & 0,07 \\
\hline 1995 & 100,00 & 83,32 & 4,24 & 2,57 & 9,87 & 0,05 \\
\hline 1996 & 100,00 & 83,93 & 3,72 & 2,71 & 9,64 & 0,04 \\
\hline 1997 & 100,00 & 85,46 & 3,69 & 2,17 & 8,68 & 0,04 \\
\hline 1998 & 100,00 & 87,63 & 3,42 & 1,87 & 7,08 & 0,09 \\
\hline 1999 & 100,00 & 88,19 & 4,02 & 1,56 & 6,23 & 0,09 \\
\hline 2000 & 100,00 & 88,73 & 3,46 & 1,3 & 6,51 & 0,12 \\
\hline 2001 & 100,00 & 88,53 & 3,41 & 1,4 & 6,66 & 0,18 \\
\hline 2002 & 100,00 & 88,11 & 3,5 & 2,06 & 6,34 & 0,41 \\
\hline 2003 & 100,00 & 87,57 & 3,77 & 2,24 & 6,42 & 0,59 \\
\hline 2004 & 100,00 & 87,51 & 3,63 & 2,1 & 6,76 & 0,52 \\
\hline 2005 & 100,00 & 85,68 & 4,27 & 2,23 & 7,82 & 0,53 \\
\hline 2006 & 100,00 & 84,75 & 4,4 & 2,55 & 8,3 & 0,68 \\
\hline 2007 & 100,00 & 82,07 & 5,35 & 2,8 & 9,77 & 0,7 \\
\hline 2008 & 100,00 & 80,15 & 5,93 & 2,96 & 10,95 & 0,7 \\
\hline 2009 & 100,00 & 80,59 & 5,06 & 3,29 & 11,06 & 0,96 \\
\hline 2010 & 100,00 & 79,97 & 4,84 & 3,59 & 11,61 & 1,4 \\
\hline \multicolumn{7}{|c|}{ Importaciones } \\
\hline 1993 & 100,00 & 69,29 & 12,1 & 11,28 & 7,33 & 0,59 \\
\hline 1994 & 100,00 & 69,11 & 11,59 & 11,93 & 7,37 & 0,63 \\
\hline 1995 & 100,00 & 74,4 & 9,43 & 10,63 & 5,55 & 0,72 \\
\hline 1996 & 100,00 & 75,49 & 8,8 & 10,06 & 5,66 & 0,85 \\
\hline 1997 & 100,00 & 74,68 & 9,25 & 10,3 & 5,77 & 1,14 \\
\hline 1998 & 100,00 & 74,38 & 9,57 & 10,24 & 5,81 & 1,29 \\
\hline 1999 & 100,00 & 74,15 & 9,28 & 10,66 & 5,92 & 1,35 \\
\hline 2000 & 100,00 & 73,1 & 8,79 & 11,62 & 6,49 & 1,65 \\
\hline 2001 & 100,00 & 67,56 & 10 & 15,05 & 7,39 & 2,39 \\
\hline 2002 & 100,00 & 63,17 & 10,16 & 18,59 & 8,08 & 3,72 \\
\hline 2003 & 100,00 & 61,78 & 10,93 & 18,68 & 8,61 & 5,51 \\
\hline 2004 & 100,00 & 56,31 & 11,07 & 22,56 & 10,06 & 7,3 \\
\hline 2005 & 100,00 & 53,44 & 11,71 & 24,19 & 10,66 & 7,98 \\
\hline 2006 & 100,00 & 50,89 & 11,33 & 26,91 & 10,87 & 9,54 \\
\hline 2007 & 100,00 & 49,47 & 12 & 28,18 & 10,36 & 10,55 \\
\hline 2008 & 100,00 & 49,04 & 12,7 & 27,94 & 10,33 & 11,24 \\
\hline 2009 & 100,00 & 47,97 & 11,62 & 30,79 & 9,63 & 13,88 \\
\hline 2010 & 100,00 & 48,1 & 10,78 & 31,82 & 9,31 & 15,13 \\
\hline \multicolumn{7}{|c|}{ Comercio total } \\
\hline 1993 & 100,00 & 75,23 & 9,05 & 7,44 & 8,28 & 0,37 \\
\hline 1994 & 100,00 & 75,91 & 8,61 & 7,85 & 7,62 & 0,39 \\
\hline 1995 & 100,00 & 79,07 & 6,71 & 6,41 & 7,81 & 0,37 \\
\hline 1996 & 100,00 & 79,86 & 6,17 & 6,25 & 7,72 & 0,43 \\
\hline 1997 & 100,00 & 80,09 & 6,46 & 6,22 & 7,23 & 0,59 \\
\hline 1998 & 100,00 & 80,79 & 6,59 & 6,19 & 6,42 & 0,71 \\
\hline 1999 & 100,00 & 81,03 & 6,71 & 6,2 & 6,07 & 0,74 \\
\hline 2000 & 100,00 & 80,73 & 6,19 & 6,59 & 6,5 & 0,91 \\
\hline 2001 & 100,00 & 77,74 & 6,8 & 8,43 & 7,04 & 1,32 \\
\hline 2002 & 100,00 & 75,35 & 6,9 & 10,51 & 7,23 & 2,1 \\
\hline 2003 & 100,00 & 74,45 & 7,41 & 10,6 & 7,53 & 3,09 \\
\hline 2004 & 100,00 & 71,55 & 7,44 & 12,56 & 8,45 & 3,99 \\
\hline 2005 & 100,00 & 69,28 & 8,06 & 13,4 & 9,26 & 4,32 \\
\hline 2006 & 100,00 & 67,61 & 7,91 & 14,88 & 9,6 & 5,16 \\
\hline 2007 & 100,00 & 65,47 & 8,73 & 15,72 & 10,07 & 5,71 \\
\hline 2008 & 100,00 & 64,15 & 9,41 & 15,81 & 10,63 & 6,12 \\
\hline 2009 & 100,00 & 64,12 & 8,37 & 17,17 & 10,34 & 7,48 \\
\hline 2010 & 100,00 & 63,95 & 7,82 & 17,77 & 10,45 & 8,3 \\
\hline
\end{tabular}

Fuente: elaborado por los autores sobre la base de datos del Banco de México (Banxico). 


\section{La cadena hilo-textiles-confección}

La cadena hilo-textiles-confección es una de las cadenas mundiales que han cambiado con mayor rapidez en las últimas décadas. Las tendencias en este sector en los últimos 10 años incluyen: la creciente saturación relativa a las confecciones en los países desarrollados; la profundización de los procesos completos de embalaje - los proveedores son cada vez más responsables de los costos de la manufactura, desde la compra de insumos hasta su financiación (también en el sector de servicios: transporte, aduana, logística y coordinación y distribución de productos en el mercado consumidor final, entre otros)_-; la diferenciación cada vez mayor de los productos, incluidos los que cumplen con estándares éticos y ecológicos; la creciente influencia y el control de la cadena por los comerciantes al por menor; la drástica reducción de los tiempos de producción y entrega, y la dura competencia a nivel mundial que afecta a los precios. Como resultado, la existencia y el fortalecimiento de un sistema de proveedores locales es fundamental para hacer frente a esos retos (Dussel Peters, 2010a). A comienzos del siglo XXI, la cadena (controlada por sus compradores y clientes) parece encontrarse en un período más liberal en comparación con las últimas décadas, en virtud del fin del Acuerdo Multifibras (AMF) en 2005, la pronunciada reducción de las intervenciones públicas —en términos de barreras arancelarias y no arancelarias y subsidios gubernamentales - y la concentración de instrumentos de apoyo en la industria textil y de accesorios y, en menor grado, en la industria de la vestimenta (Frederick y Gereffi, 2009).

Además de estas tendencias, hubo una rápida "reorientalización" de la cadena hilo-textiles-confección. Mientras que la participación en la producción y el comercio mundial de China, la India, Bangladesh y el Pakistán, entre otros países, se ha acrecentado considerablemente en la primera década del siglo XXI, la producción y el comercio de los países desarrollados ha disminuido en forma constante desde los años ochenta del siglo pasado. En el caso de los Estados Unidos de América, por ejemplo, mientras que la industria textil y de prendas de vestir representaba 1,1 millón de puestos de trabajo en 2000, esa cifra se había reducido más de un $50 \%$ en 2008 y se prevé que disminuirá un 22,6\% más en 2016 (Oficina de Estadísticas Laborales, 2009).

En México, la cadena hilo-textiles-confección es uno de los símbolos de la integración mundial y del TLCAN. Sobre la base de la última matriz de insumo-producto de la economía mexicana en 2003 (Dussel Peters, 2010a), esta matriz presenta varias características distintivas.
Por una parte, se observan marcadas diferencias entre los segmentos que utilizan la industria maquiladora y los demás. La cadena representa niveles más altos de insumos importados con respecto a los insumos totales que el resto de la industria manufacturera. Estos corresponden al $33,1 \%$ en el caso de la cadena hilotextiles-confección y al 38,2\% en el segmento textil. En 2003, el comercio exterior representó el 51\% de la producción y el $60 \%$ del segmento de las prendas de vestir. A pesar del alto nivel de integración en el mercado mundial, la cadena tiene una profunda debilidad estructural: su alto componente de importaciones netas. En el caso de la industria maquiladora, el contenido nacional de toda la economía, la industria manufacturera, la cadena hilo-textiles-confección y el segmento textil era de $0,3 \%, 3,1 \%, 4,7 \%$ y $15,7 \%$, respectivamente. Esta estructura es el resultado de complejos incentivos vinculados a importaciones temporales para su exportación (Cárdenas Castro y Dussel Peters, 2007). Por otra parte, la cadena hilo-textiles-confección se destaca por pagar impuestos (sobre la producción) $45 \%$ más altos que en la economía mexicana en general (en el caso de las prendas de vestir, los impuestos eran $63 \%$ más altos), por los pagos por empleado (23\% más bajos que en la economía en general, con excepción del segmento textil), y por ser especialmente sensible a la creación de puestos de trabajo como resultado de la sustitución de importaciones: un aumento del $10 \%$ de la demanda final por la vía de la sustitución de importaciones se traduciría en un incremento de 17.000 empleos en la cadena hilo-textiles-confección, sobre todo en el sector de la indumentaria. Solo 5 de las 75 actividades de toda la economía generarían más empleo que esta cadena (Dussel Peters, 2010a).

Teniendo en cuenta la orientación cada vez mayor de la cadena hilo-textiles-confección hacia el comercio exterior (y la participación del $60 \%$ de la producción de prendas de vestir en 2003), ¿cuáles son sus principales características en términos de producción, empleo, comercio e integración en el mercado de los Estados Unidos de América y su relación con China?

En primer lugar, en 2009 la cadena hilo-textilesconfección representó el $0,9 \%$ y el $5 \%$ del valor agregado bruto total y de las manufacturas de México, respectivamente. En los datos del cuadro 7 se refleja el pronunciado movimiento cíclico de la cadena en la primera etapa del TLCAN (hasta 2000) y la reducción de los indicadores relativos al PIB y el empleo desde entonces. En términos del PIB, si bien la industria manufacturera se ha recuperado lentamente desde 2005 (su PIB creció solo un $7 \%$ en 10 años), la proporción del valor agregado 


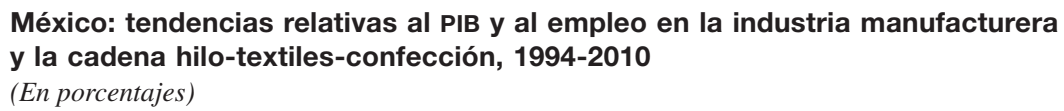

\begin{tabular}{|c|c|c|c|c|c|c|c|c|c|}
\hline & 1994 & 1995 & 1996 & 1997 & 1998 & 1999 & 2000 & 2001 & 2002 \\
\hline \multicolumn{10}{|l|}{ PIB $(2000=100)$} \\
\hline Industria manufacturera & 72,77 & 68,77 & 75,94 & 83,90 & 89,93 & 93,90 & 100,00 & 96,13 & 95,10 \\
\hline Cadena hilo-textiles-confección & 76,42 & 71,51 & 82,33 & 89,44 & 92,54 & 96,63 & 100,00 & 90,15 & 84,46 \\
\hline \multicolumn{10}{|l|}{ Empleo $(2000=100)$} \\
\hline Industria manufacturera & 71,84 & 70,07 & 74,97 & 83,48 & 88,54 & 93,95 & 100,00 & 95,99 & 90,84 \\
\hline Cadena hilo-textiles-confección & 94,34 & 85,38 & 90,99 & 96,38 & 98,26 & 98,85 & 100,00 & 90,91 & 83,65 \\
\hline \multirow[t]{2}{*}{ Prendas de vestir } & 91,34 & 81,02 & 86,98 & 92,05 & 100,30 & 101,45 & 100,00 & 91,74 & 83,56 \\
\hline & 2003 & 2004 & 2005 & 2006 & 2007 & 2008 & 2009 & 2010 & \\
\hline \multicolumn{10}{|l|}{ PIB $(2000=100)$} \\
\hline Industria manufacturera & 93,75 & 97,44 & 100,91 & 106,89 & 108,74 & 107,95 & 97,38 & 107,03 & \\
\hline Cadena hilo-textiles-confección & 78,58 & 79,68 & 77,61 & 78,07 & 75,10 & 73,83 & 69,11 & 74,04 & \\
\hline \multicolumn{10}{|l|}{ Empleo $(2000=100)$} \\
\hline Industria manufacturera & 87,20 & 86,86 & 87,24 & 88,60 & 88,83 & 85,88 & 77,30 & 80,70 & \\
\hline Cadena hilo-textiles-confección & 77,27 & 71,67 & 68,65 & 66,52 & 64,52 & 60,11 & 54,86 & 55,47 & \\
\hline Prendas de vestir & 77,60 & 71,97 & 67,15 & 66,07 & 63,74 & 58,68 & 53,27 & 52,75 & \\
\hline
\end{tabular}

Fuente: elaborado por los autores sobre la base de Instituto Nacional de Estadística y Geografía (INEGI), Encuesta Industrial Mensual (EIM) y Sistema de Cuentas Nacionales de México (SCN).

PIB: producto interno bruto.

bruto de la cadena hilo-textiles-confección con respecto al total es inferior al alcanzado antes del TLCAN y se redujo más de un cuarto en 2010 en comparación con 2000. Este desempeño, que también obedece al crecimiento de la productividad y de las nuevas formas de organización industrial mencionadas en el capítulo anterior, es aún más marcado con respecto al empleo: mientras que en el sector manufacturero mexicano se perdieron casi un millón de puestos de trabajo en el período 2000-2010 (o un cuarto del empleo total en el sector), en la cadena hilo-textiles-confección se perdieron casi la mitad de los puestos de trabajo desde 2000, a pesar de las ganancias iniciales en el período 1994-2000. Estas pérdidas han sido particularmente acentuadas en el segmento de la indumentaria. Toda la cadena representaba más de medio millón de puestos de trabajo en 2009 (INEGI, 2010a).

En segundo lugar, en el período 1995-2010, el $69,76 \%$ de las exportaciones mexicanas de la cadena hilotextil-confección correspondían al segmento de prendas de vestir ${ }^{6}$, seguido por textiles $(9,6 \%)$, hilados $(8,97 \%)$

\footnotetext{
${ }^{6}$ La cadena hilo-textiles-confección es un conjunto de 5.503 fracciones a nivel de 10 dígitos del Sistema Armonizado de Aranceles. En el caso del comercio de los Estados Unidos de América — que registra
}

y otros accesorios $(12,40 \%)$. En el gráfico 3 se refleja la dinámica diferenciada de esta cadena mexicana antes y después del año 2000, con una tasa media de crecimiento anual de las exportaciones del $20,7 \%$ y el $-5,4 \%$ en los períodos 1995-2000 y 2000-2010, respectivamente. En el período 1995-2010, los Estados Unidos de América representaban el 90,6\% de las exportaciones de la cadena hilo-textiles-confección mexicana. Este desempeño diferenciado es particularmente llamativo en el segmento de las prendas de vestir (véase el gráfico 4). Es bastante sorprendente que la balanza comercial de México en la cadena mencionada se volviera negativa en 2006 (véase el gráfico 4) como resultado de una contracción de las exportaciones de prendas de vestir desde 2001 y un aumento en los insumos importados para las cadenas.

En tercer lugar, y teniendo en cuenta la elevada concentración de las exportaciones de la cadena hilo-

un comercio a nivel de 10 dígitos, por ejemplo, se cuentan artículos de fibras e hilo (493 artículos), textiles (1.575), prendas de vestir (2.985) y otros insumos (450) al nivel de 8 dígitos (para México, por ejemplo) — los artículos cambian con el tiempo a medida que aparecen nuevos productos y otros viejos desaparecen del Sistema Armonizado de Aranceles. Véase más información sobre este tema en Cárdenas Castro y Dussel Peters (2007) y Dussel Peters (2004). 
GRÁFICO 3

México: exportaciones de la cadena hilo-textiles-confección por segmento, 1995-2010

(Tasa media de crecimiento anual)

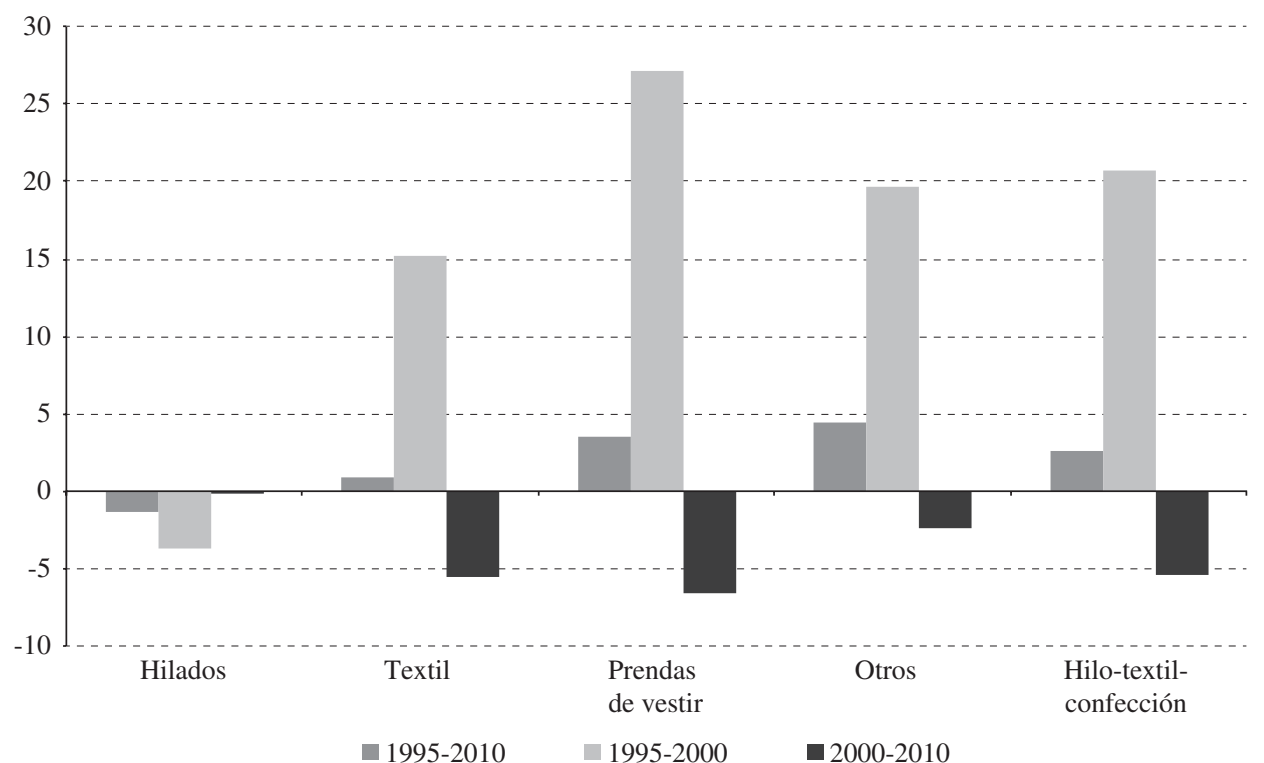

Fuente: elaborado por los autores sobre la base de datos de la Comisión de Comercio Internacional de los Estados Unidos, 2010.

GRÁFICO 4

México: balanza comercial por segmentos principales, 1995-2010

(En millones de dólares)

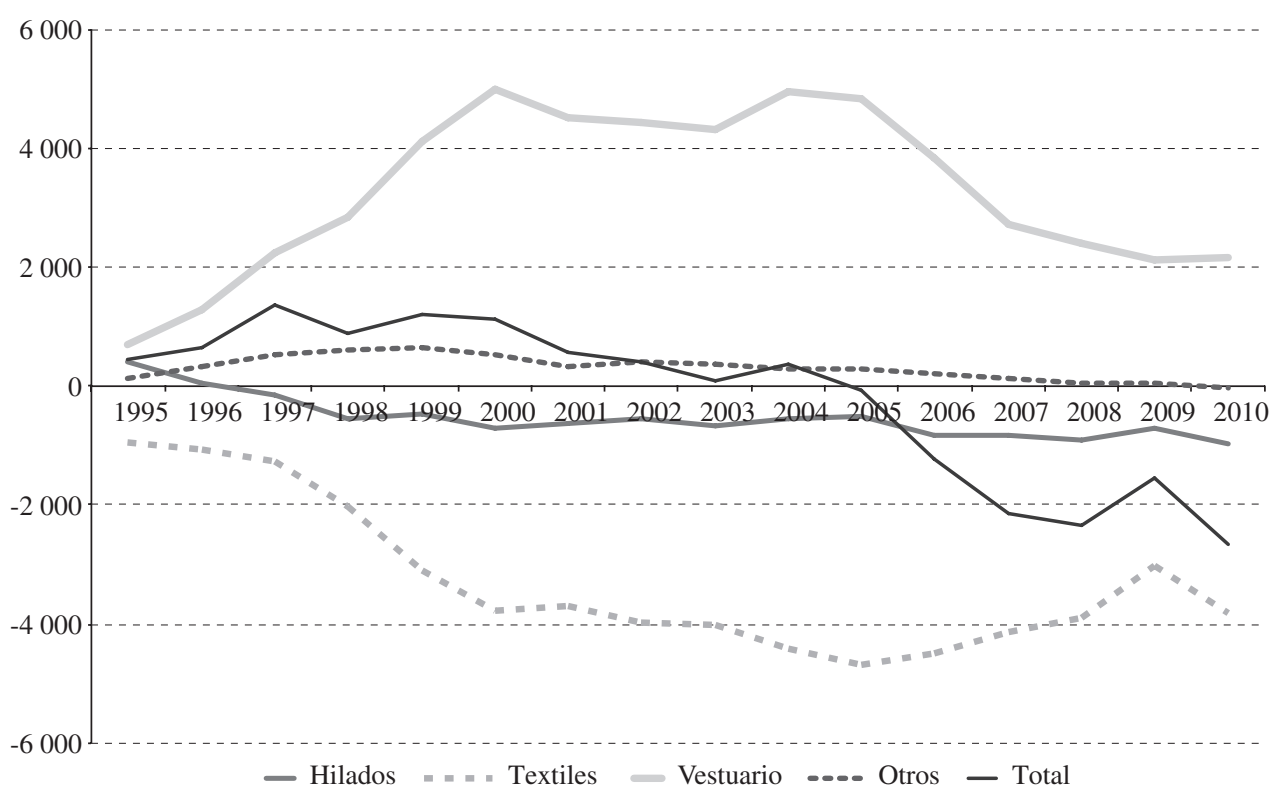

Fuente: elaborado por los autores sobre la base de datos del Centro de Estudios China-México, 2011. 
textiles-confección mexicana a los Estados Unidos de América, se observan varios problemas que ponen de relieve la creciente desintegración de la organización industrial de la cadena regional en la zona del TLCAN. En el cuadro 8 se aprecia que las exportaciones mexicanas de este tipo de productos a los Estados Unidos de América aumentaron considerablemente en los años noventa y disminuyeron una vez más desde entonces, con una tasa media de crecimiento anual del $30,7 \%$ y el $-4,4 \%$ en los períodos $1990-2000$ y $2000-2010$, respectivamente. La participación mexicana en las importaciones estadounidenses totales en la cadena hilo-textiles-confección llegó a su máximo nivel en 1999, cuando alcanzó el 13,27\%, y se contrajo en forma constante hasta llegar a un 6,51\% en 2010. Mientras tanto la participación de China pasó del $12,41 \%$ al $42,1 \%$ en igual período. Se destaca la importancia de otros dos aspectos: i) el coeficiente de importación/exportación de los Estados Unidos de América — que constituye una variable sustitutiva para medir el contenido estadounidense de las importaciones de ese país- muestra que México y Centroamérica son grandes consumidores de la cadena hilo-textiles-confección estadounidense, en comparación con el resto del mundo y China. En otras palabras, México no es solo un importante exportador a los Estados
Unidos de América, sino también el país con el mayor valor agregado estadounidense en sus exportaciones, lo que refleja un profundo nivel de integración regional; y ii) también a raíz del TLCAN, México todavía goza de enormes incentivos arancelarios, pues en el período 2000-2010 pagó solo un 4,62\% de los aranceles pagados por todas las importaciones estadounidenses de esta cadena en particular. Los aranceles en la cadena hilotextiles-confección son considerables y aquellos pagados por los países asiáticos son mucho más altos que los de México (véase el cuadro 8).

En cuarto lugar, mientras México enfrenta una competencia cada vez mayor en el mercado estadounidense, la producción de materiales (telas y accesorios textiles) ha disminuido, sobre todo en el caso de las fibras sintéticas como el poliéster y el rayón, en tanto que los productos de lana y algodón todavía son bastante competitivos y aún no han sido desplazados por los productores asiáticos y chinos ${ }^{7}$.

\footnotetext{
${ }^{7}$ A nivel desagregado, México todavía es un exportador decisivo a los Estados Unidos de América de productos de dril y algodón para hombres y mujeres. Algunos ejemplos son los artículos 6203424011 (pantalones de hombre de algodón y dril azul y pantalones de algodón que no sean de punto) y 6204624011 (pantalones de mujer de algodón y
}

Estados Unidos de América: importaciones de la cadena hilo-textiles-confección, 1990-2010

\begin{tabular}{|c|c|c|c|c|c|}
\hline & \multicolumn{5}{|c|}{ Proporción de las importaciones totales } \\
\hline & 1990 & 2000 & 2010 & $1990-2000$ & $2000-2010$ \\
\hline China & 11,44 & 12,02 & 42,10 & 13,07 & 27,13 \\
\hline Viet Nam & 0,00 & 0,06 & 4,80 & 0,04 & 3,28 \\
\hline México & 2,98 & 13,22 & 6,51 & 9,34 & 8,45 \\
\hline India & 3,17 & 3,85 & 2,48 & 3,77 & 4,48 \\
\hline \multirow[t]{2}{*}{ Total importaciones } & 100,00 & 100,00 & 100,00 & 100,00 & 100,00 \\
\hline & \multicolumn{5}{|c|}{ Coeficiente importación/exportación (en porcentajes) } \\
\hline China & 5,498 & 20,518 & 25,329 & 10,070 & 26,956 \\
\hline Viet Nam & $\ldots$ & 6,093 & 95,909 & 3,043 & 91,020 \\
\hline México & 309 & 754 & 783 & 674 & 732 \\
\hline India & 10,398 & 25,542 & 10,849 & 14,323 & 26,933 \\
\hline Indonesia & 16,005 & 28,242 & 24,579 & 17,729 & 38,757 \\
\hline Total importaciones & \multicolumn{5}{|c|}{ Aranceles para las importaciones (total = 100) } \\
\hline China & 92,66 & 105,24 & 118,45 & 99,23 & 114,14 \\
\hline Viet Nam & $\ldots$ & 371,4 & 5,09 & 316,41 & 137,48 \\
\hline México & 85,76 & 3,38 & 2,16 & 14,29 & 4,62 \\
\hline India & 86,12 & 109,69 & 8,78 & 101,99 & 102,71 \\
\hline Indonesia & 124,88 & 159,46 & 19,39 & 147,27 & 163,39 \\
\hline Total importaciones & 100 & 100 & 100 & 100 & 100 \\
\hline
\end{tabular}

Fuente: elaborado por los autores sobre la base de datos de la Comisión de Comercio Internacional de los Estados Unidos, 2011. 
Por último, en términos cualitativos, los empresarios mexicanos (Dussel Peters, 2010a) han solicitado abiertamente la modernización del TLCAN. Después de más de 17 años, el marco de integración regional del acuerdo es anticuado, pues se creó a comienzos de los años noventa sobre la base de una organización industrial de fines de los años ochenta que ya no existe. La mayoría de los productores textiles y de accesorios han dejado la región y Asia se ha convertido en el principal productor mundial de estos artículos. Además, los Estados Unidos de América han concedido grandes beneficios a los otros países con los que han firmado acuerdos de libre comercio y que no forman parte del TLCAN. En consecuencia, desde esta perspectiva empresarial, las normas de origen y otros requisitos legales del TLCAN son cada vez más obsoletos e imposibles de cumplir, mientras que las autoridades estadounidenses han creado un conjunto de instrumentos de vigencia anual para superar estas limitaciones regionales. Sin embargo, el marco actual del TLCAN y los incentivos anuales para que algunos productos que no cumplirían con las normas de origen lo hagan, han debilitado la cadena hilo-textiles-confección mexicana y regional, pues las empresas no pueden depender de

dril azul y pantalones de algodón que no sean de punto). Sin embargo, con respecto a los productos relacionados con fibras sintéticas y nylon, como los artículos 6203434010 (calzoncillos y ropa interior para hombres en fibra sintética sin coser) y 6204633510 (bragas y ropa interior para mujeres en fibra sintética sin coser), la participación de México en las exportaciones totales y en las importaciones estadounidenses se ha reducido drásticamente. un proceso de toma de decisiones mensual y anual para operaciones y estrategias a largo plazo.

\section{La cadena autopartes-automotriz}

La cadena autopartes-automotriz no solo fue una de las primeras que comenzaron a transferir segmentos de su cadena de valor a nivel internacional (Piore y Sabel, 1984), sino que también — a diferencia de la cadena hilotextiles-confección- está impulsada por el productor. A raíz de las preferencias de los consumidores, de factores arancelarios y de intervenciones del sector público para incentivar la producción y a las empresas nacionales y locales, la cadena autopartes-automotriz se ha regionalizado cada vez más. Asimismo, se ha caracterizado por: i) la formación de "módulos" que pueden transferirse; ii) el surgimiento de importantes problemas y estándares ecológicos, ambientales y de eficiencia que han producido una nueva dinámica de innovación y competencia en el campo de los vehículos híbridos y eléctricos, y iii) la movilización masiva de recursos nacionales para incrementar la producción interna, sobre todo a partir de la crisis internacional de 2007-2008 (Rodrik, 2010; Sturgeon, Biesebroeck y Gereffi, 2008).

Para comprender la organización industrial específica en la zona del TLCAN y su relación con China es necesario tener en cuenta varias tendencias internacionales. En primer lugar, las profundas reformas espaciales de la cadena autopartes-automotriz en las últimas décadas (véase el cuadro 9). Mientras que la participación estadounidense en el mercado ha disminuido considerablemente, pasando

CUADRO 9

Participación en la producción internacional de automóviles, 1961-2010

(En porcentajes)

\begin{tabular}{|c|c|c|c|c|c|c|c|c|c|c|}
\hline & 1961 & 1971 & 1981 & 1991 & 1999 & 2000 & 2005 & 2008 & 2009 & 2010 \\
\hline Estados Unidos de América & 48,5 & 32,5 & 22,8 & 15,4 & 23,2 & 21,9 & 18,0 & 12,3 & 9,3 & 10,0 \\
\hline Reino Unido de Gran Bretaña e Irlanda del Norte & 8,8 & 6,6 & 3,5 & 3,5 & 3,5 & 3,1 & 2,7 & 2,3 & 1,8 & 1,8 \\
\hline Italia & 6,1 & 6,4 & 4,6 & 4,6 & 3,0 & 3,0 & 1,6 & 1,5 & 1,4 & 1,1 \\
\hline Alemania & 15,8 & 14,5 & 13,7 & 13,3 & 10,1 & 9,5 & 8,7 & 8,6 & 8,4 & 7,6 \\
\hline Francia & 8,7 & 10,2 & 9,5 & 9 & 5,7 & 5,7 & 5,3 & 3,6 & 3,3 & 2,9 \\
\hline México & $\ldots$ & 0,6 & 1,3 & 2 & 2,8 & 3,3 & 2,5 & 3,1 & 2,5 & 3,0 \\
\hline Japón & 2,2 & 14,1 & 25,4 & 27,6 & 17,6 & 17,4 & 16,2 & 16,4 & 12,9 & 12,4 \\
\hline China & $\ldots$ & $\ldots$ & $\ldots$ & 0,2 & 3,3 & 3,5 & 8,6 & 13,3 & 22,4 & 23,5 \\
\hline España & 0,5 & 1,7 & 3,1 & 5,5 & 5,1 & 5,2 & 4,1 & 3,6 & 3,5 & 3,1 \\
\hline Brasil & 0,9 & 1,3 & 1,5 & 2 & 2,4 & 2,9 & 3,8 & 4,6 & 5,2 & 4,7 \\
\hline República de Corea & $\ldots$ & $\ldots$ & 0,3 & 3,3 & 5,1 & 5,3 & 5,6 & 5,4 & 5,7 & 5,5 \\
\hline India & 0,2 & 0,2 & 0,2 & 0,5 & 1,5 & 1,4 & 2,5 & 3,3 & 4,3 & 4,6 \\
\hline Mundo & 11,391 & 26,453 & 27,407 & 35,287 & 56,259 & 58,374 & 66,482 & 70,527 & 61,715 & 77,610 \\
\hline
\end{tabular}

Fuente: elaborado por los autores sobre la base de datos de la Organización Internacional de Constructores de Automóviles (OICA). 
de niveles cercanos al 50\% de la producción mundial en los años sesenta al $15 \%$ en la primera mitad de los años noventa y al $10 \%$ en $2010^{8}$, la producción del Japón fue en aumento hasta la década de 1990 alcanzando niveles superiores al $25 \%$ y disminuyó en forma constante a partir de ese momento hasta llegar a un 12,9\% en 2010. Por otra parte, la producción de un grupo de países emergentes como el Brasil, China, la India, México y la República de Corea se incrementó notablemente hasta sobrepasar el $40 \%$ en 2010. China, que se convirtió en el principal productor mundial en 2009 y representaba el $23,5 \%$ de la producción en 2010, es probablemente uno de los casos más destacados en la historia de los automóviles, teniendo en cuenta que en la primera mitad de los años noventa su participación en la producción todavía era inferior a un $1 \%$. En el caso de México, su participación creció en los años noventa hasta llegar a un 3,3\% en 2000-2001, para luego disminuir a un 3\% en 2010.

En segundo lugar, estas tendencias regionales se han acentuado desde la crisis mundial de 2008-2009: mientras que la producción de vehículos decayó y registró tasas medias de crecimiento anual de $-5,1 \%$, $-5,5 \%,-8,8 \%$ y de un $4,7 \%$ en la Unión Europea, los Estados Unidos de América, el Japón y a nivel mundial, respectivamente, la tasa media de crecimiento anual en China fue del 40,1\% en el período 2008-2010. Solo unos pocos países emergentes, como la India y México, con una tasa media de crecimiento anual del $23,1 \%$ y el 4,0\%, respectivamente, también se recuperaron con rapidez después de la crisis o no registraron ningún descenso de la producción.

En tercer lugar, si bien en 2009 se destaca el predominio constante de las empresas instaladas en el Japón, los Estados Unidos de América y Europa (Toyota, General Motors, Volkswagen, Ford y Hyundai encabezaron la producción total de vehículos), 21 empresas chinas se encuentran ahora entre los primeros 50 productores de automóviles del mundo. Aunque ninguna de ellas se encuentra entre las 10 primeras, ya están comenzando a situarse entre las primeras 20 .

¿Cuáles son las principales tendencias de la cadena autopartes-automotriz mexicana con respecto a los Estados Unidos de América y el TLCAN? En México, el mercado automotor y sus segmentos representaron el $2,7 \%$ del PIB y el 16\% de la producción manufacturera en 2009, y

\footnotetext{
${ }^{8}$ En los Estados Unidos de América no solo se ha registrado una marcada contracción de las ventas de vehículos nuevos, de más de 17 millones de unidades en 2000-2006 a 10,6 millones y 11,5 millones en 2009 y 2010, respectivamente, sino también una penetración masiva de marcas asiáticas en las importaciones estadounidenses en general, que representó más del 35\% en 2010 (SE, 2011).
}

constituyen el sector que se recuperó con mayor rapidez luego de la crisis mundial de 2008-2009 en términos de producción, empleo y exportaciones (Monitor de la Manufactura Mexicana, 2012). En la actualidad existen 13 plantas de fabricantes de equipos originales dedicadas a la producción de vehículos para pasajeros y otras 11 a la de vehículos comerciales. Las exportaciones son el destino primario de la producción de la cadena autopartesautomotriz en México y representan el 78\% del total (INEGI, 2010a). Desde este punto de vista, la crisis de 1994-1995 y el establecimiento del TLCAN marcaron un punto de inflexión tendiente a la nueva orientación exportadora. Del cuadro 9 se desprende que la producción de vehículos casi se duplicó en la primera etapa del TLCAN (1994-2000), pero se mantuvo relativamente estable en el período 2006-2010, con una marcada disminución durante la crisis y una rápida recuperación en 2010.

La cadena autopartes-automotriz en México es el resultado de una larga historia de incentivos, que incluyen la aprobación de cinco decretos entre 1962 y 1993 (con el último de los cuales se apuntaba a lograr determinados niveles de valor agregado en México), así como disposiciones y requisitos tecnológicos relacionados, entre otros propósitos, con la balanza comercial. Con el TLCAN, las normas de origen regionales gobiernan la organización industrial de México: el valor de contenido regional - medido sobre la base del valor de la transacción y el costo neto- establecido en el Artículo 401 del TLCAN permite reducciones arancelarias a la producción regional. Desde 2002, el nivel de valor agregado ha sido reemplazado por normas de origen regionales $(62,6 \%$ para los automóviles) con el objetivo de evitar que empresas extranjeras se valieran de México como plataforma de exportación a los Estados Unidos de América (Dussel Peters, Ruiz Durán y Taniura, 1997; Hufbauer y Schott, 2005). Por otra parte, México también cuenta con su propia legislación dirigida a promover ventajas competitivas para la cadena autopartes-automotriz (DOF, 2003) y con varios decretos posteriores hasta 2010. En general, la legislación mexicana requiere el cumplimiento de una serie de disposiciones por parte de los nuevos fabricantes de vehículos (al contrario de las partes y piezas) con un peso de hasta $8.864 \mathrm{~kg}$ :

i) Fabricar por lo menos 50.000 unidades;

ii) invertir en México por lo menos 100 millones de dólares en activo fijo para la producción automotriz;

iii) establecer acuerdos con distribuidores de vehículos; y

iv) en el caso de los nuevos fabricantes sin producción previa en México, además de los puntos i) a iii), se concede un permiso excepcional para importar 
vehículos sin tasas arancelarias ad valórem durante los primeros tres años a partir de la instalación de un nuevo fabricante para el $10 \%$ de la producción 9 . Este criterio se mantiene incluso después de los primeros tres años de producción.

La cadena autopartes-automotriz en México presenta un conjunto de características particulares (Dussel Peters, Ruiz Durán y Taniura 1997; INEGI 2010b; SE, 2008). En primer término, al tener en cuenta que esta cadena está compuesta por cuatro grandes segmentos (montaje, componentes más grandes y premontaje, partes y componentes, y materias primas), se observa que ninguna de las 18 empresas de montaje en el primer segmento es mexicana. En el sector de partes y componentes se cuentan alrededor de 1.000 fabricantes nacionales y extranjeros, 345 de los cuales son empresas de primer nivel (AMDA/AMIA/INA, 2009; SE, 2011). En segundo lugar, la cadena autopartes-automotriz es paradigmática para México debido a que se ha orientado radicalmente a las exportaciones. A diferencia de su estructura en los años ochenta —es decir, desde la aprobación del TLCAN-, esta cadena mexicana está profundamente integrada con la de los Estados Unidos de América, a tal punto que se podría hablar de una cadena autopartes-automotriz regional, con modelos, insumos, productos y procesos regionales. En el cuadro 10 se muestra la manera en que los segmentos de la cadena autopartes-automotriz han experimentado esta orientación a las exportaciones, tanto con respecto a los automóviles como a los camiones ${ }^{10}$.

Sin embargo, el mercado interno no se ha recuperado en forma significativa, y en el período 2008-2010 aún registraba niveles muy inferiores a los de comienzos de la década de 2000. En tercer lugar, la cadena autopartesautomotriz ha cobrado cada vez más importancia en el comercio exterior mexicano. En 2010 representaba el $28 \%$ de las exportaciones y el $17 \%$ de las importaciones del país, y producía un superávit anual en la balanza comercial de más de 20.000 millones de dólares desde 2006. Esto la convirtió en la cadena con el mayor superávit comercial de México. Las exportaciones del segmento de partes y componentes se han incrementado considerablemente y

${ }^{9} \mathrm{El}$ arancel de importación era del $40 \%$ hasta 2009 , del $30 \%$ en 2010-2011 y del $20 \%$ en 2012. De acuerdo con diferentes empresas, esta marcada reducción puede traducirse en considerables nuevas inversiones e importaciones de terceros países. Con respecto a las partes y piezas, el $80 \%$ de 1.837 fracciones arancelarias estaban libres de impuestos en 2010, mientras que las restantes no pagaban aranceles superiores al 5\% (SE, 2011).

${ }^{10} \mathrm{Al}$ igual que en el caso de la cadena hilo-textiles-confección, la cadena autopartes-automotriz está compuesta por 491 artículos al nivel de 10 dígitos del Sistema Armonizado de Aranceles (96 artículos en la cadena automotriz y 395 en la de autopartes). representaron el $57 \%$ de las exportaciones de la cadena autopartes-automotriz en el lapso 1995-2010. En cuarto lugar, al realizar un análisis por país, se aprecia que si bien el 93\% de las exportaciones de la cadena autopartesautomotriz de México se dirigieron a los Estados Unidos de América y el Canadá en el período 1995-2010, las importaciones estadounidenses en México disminuyeron en forma considerable. A mediados de los años noventa la participación de los Estados Unidos de América llegó a un nivel máximo del 76\%, que pasó a menos del 50\% en 2009. En otras palabras, la participación estadounidense en el mercado mexicano se ha aminorado notablemente (Dussel Peters, 2010b), (véase el cuadro 11).

Teniendo en cuenta la importancia crucial de los Estados Unidos de América para el comercio de la cadena autopartes-automotriz mexicana, en el cuadro 12 se ilustra la profunda integración de esta cadena entre los dos países. También en los Estados Unidos de América, México se ha consolidado desde el TLCAN como el principal importador: mientras que las importaciones de la cadena autopartes-automotriz mexicana representaban casi el 8\% en 1990, en 2010 el país azteca era el tercer exportador a los Estados Unidos de América (21,32\%), después del Canadá y el Japón. China —que en 1990 representaba solo un $0,11 \%$ de las importaciones estadounidenses de esta cadena - registra la mayor tasa media de crecimiento anual $(24,9 \%$ en $1990-2010)$ de los principales exportadores a los Estados Unidos de América, y sus exportaciones representaban el 3\% del total estadounidense en 2010. Además, México dispone de impresionantes ventajas arancelarias en el marco del TLCAN y solo el Canadá paga aranceles más bajos. China, por ejemplo, pagó un arancel 38 veces superior al pagado por México en 2010. Mientras que los derechos arancelarios medios en 2010 eran relativamente bajos (China pagó en promedio un 3,29\%), debido a los escasos márgenes de utilidad esta diferencia puede desempeñar un papel fundamental en el proceso final de toma de decisiones a nivel de las empresas (véase el cuadro 12).

Cabe señalar la importancia de cinco puntos finales, a saber:

i) La crisis de 2008-2010 tuvo profundas repercusiones en la cadena autopartes-automotriz en América del Norte y México y ha sido la más grave desde que comenzó a recopilarse la información comparativa. La producción de 1,6 millón de unidades en México en 2009 se redujo un $28,9 \%$, mientras que el empleo se contrajo un $21,3 \%$ entre agosto de 2007 y enero de 2010.

ii) En México se inició una impresionante trayectoria de recuperación a comienzos de 2010 y tanto las 
CUADRO 10

México: producción total de vehículos, 1988-2010

(Mercado nacional y exportaciones)

\begin{tabular}{|c|c|c|c|c|c|c|}
\hline & 1988 & 1993 & 1994 & 1995 & 2000 & 2005 \\
\hline \multirow[t]{2}{*}{ Producción total (unidades) } & 505202 & 1055221 & 1097381 & 931178 & 1889486 & 1606460 \\
\hline & \multicolumn{6}{|c|}{ Participación (en la producción total en porcentajes) } \\
\hline \multicolumn{7}{|l|}{ EXPORTACIONES } \\
\hline Vehículos & 34,49 & 46,74 & 52,40 & 83,62 & 75,84 & 74,25 \\
\hline Automóviles & 40,99 & 53,34 & 58,79 & 85,33 & 72,80 & 69,59 \\
\hline Camiones & 19,31 & 21,65 & 29,67 & 78,47 & 82,21 & 83,13 \\
\hline \multicolumn{7}{|l|}{ MERCADO NACIONAL } \\
\hline Vehículos & 65,51 & 53,26 & 47,60 & 16,38 & 24,16 & 25,75 \\
\hline Automóviles & 59,01 & 46,66 & 41,21 & 14,67 & 27,20 & 30,41 \\
\hline Camiones & 80,69 & 78,35 & 70,33 & 21,53 & 17,79 & 16,87 \\
\hline \multicolumn{7}{|l|}{ IMPORTACIONES } \\
\hline Vehículos & 3,87 & 3,99 & 10,01 & 4,00 & 23,69 & 46,98 \\
\hline Automóviles & 0,36 & 1,08 & 7,20 & 2,12 & 19,95 & 36,18 \\
\hline Camiones & 12,07 & 15,07 & 20,01 & 9,66 & 31,54 & 67,52 \\
\hline \multicolumn{7}{|c|}{ TOTAL VENTAS NACIONALES } \\
\hline Vehículos & 69,38 & 57,26 & 57,61 & 20,37 & 47,85 & 72,73 \\
\hline Automóviles & 59,38 & 47,74 & 48,41 & 16,79 & 47,15 & 66,60 \\
\hline \multirow[t]{2}{*}{ Camiones } & 92,76 & 93,42 & 90,34 & 31,19 & 49,33 & 84,39 \\
\hline & 2008 & 2009 & 2010 & $1988-1993$ & $1994-2000$ & 2000-2010 \\
\hline \multirow[t]{2}{*}{ Producción total (unidades) } & 2103801 & 1507527 & 2260776 & 5005406 & 9388600 & 20009039 \\
\hline & \multicolumn{6}{|c|}{ Participación (en la producción total en porcentajes) } \\
\hline \multicolumn{7}{|l|}{ EXPORTACIONES } \\
\hline Vehículos & 79,20 & 81,36 & 82,97 & 37,92 & 72,41 & 77,71 \\
\hline Automóviles & 79,99 & 80,26 & 80,66 & 45,59 & 70,47 & 74,40 \\
\hline Camiones & 77,54 & 83,58 & 87,25 & 15,66 & 76,63 & 84,15 \\
\hline \multicolumn{7}{|l|}{ MERCADO NACIONAL } \\
\hline Vehículos & 20,80 & 18,64 & 17,03 & 62,08 & 27,59 & 22,29 \\
\hline Automóviles & 20,01 & 19,74 & 19,34 & 54,41 & 29,53 & 25,60 \\
\hline Camiones & 22,46 & 16,42 & 12,75 & 84,34 & 23,37 & 15,85 \\
\hline \multicolumn{7}{|l|}{ IMPORTACIONES } \\
\hline Vehículos & 29,93 & 30,77 & 19,26 & 4,38 & 14,36 & 33,29 \\
\hline Automóviles & 20,94 & 22,27 & 14,96 & 1,29 & 9,86 & 26,99 \\
\hline Camiones & 48,73 & 48,01 & 27,24 & 13,35 & 24,15 & 45,56 \\
\hline \multicolumn{7}{|c|}{ TOTAL VENTAS NACIONALES } \\
\hline Vehículos & 50,73 & 49,41 & 36,29 & 66,46 & 41,95 & 55,58 \\
\hline Automóviles & 40,95 & 42,01 & 34,29 & 55,70 & 39,40 & 52,59 \\
\hline Camiones & 71,19 & 64,43 & 39,99 & 97,69 & 47,52 & 61,41 \\
\hline
\end{tabular}

Fuente: elaborado por los autores sobre la base de datos de la Asociación Mexicana de la Industria Automotriz (AMIA), 2011. 


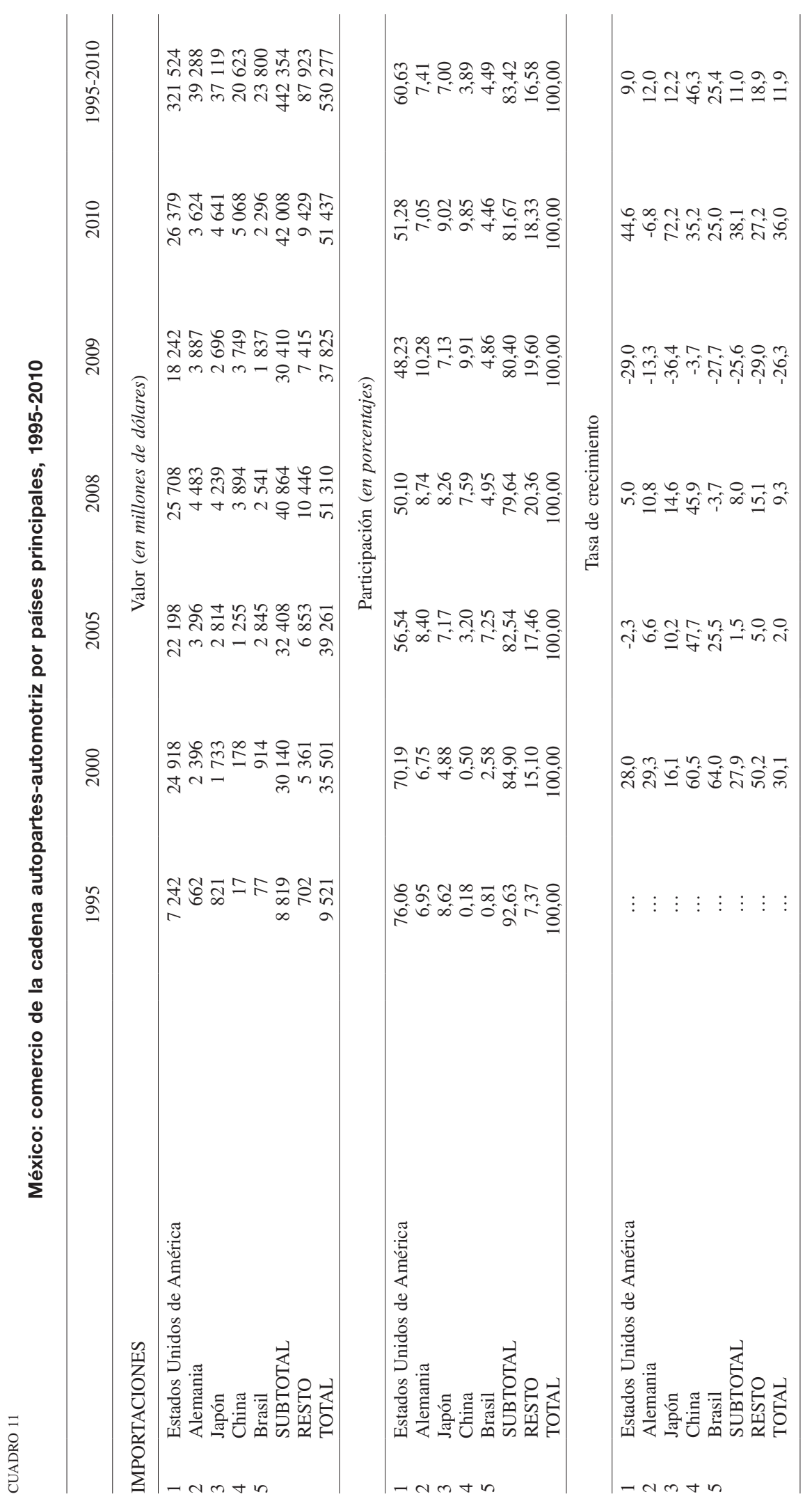




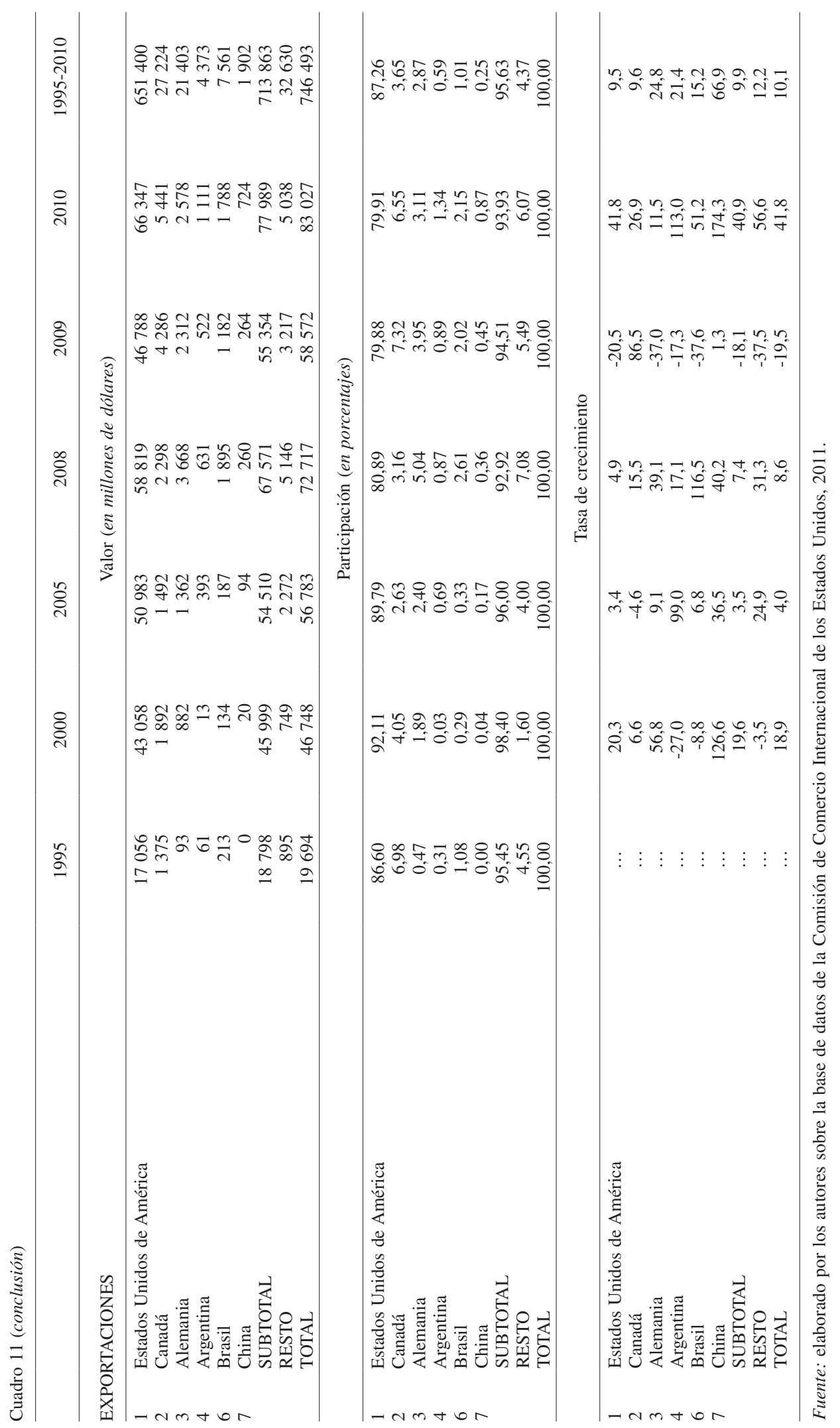


Estados Unidos de América: importaciones de países seleccionados en la cadena autopartes-automotriz, 1990-2010

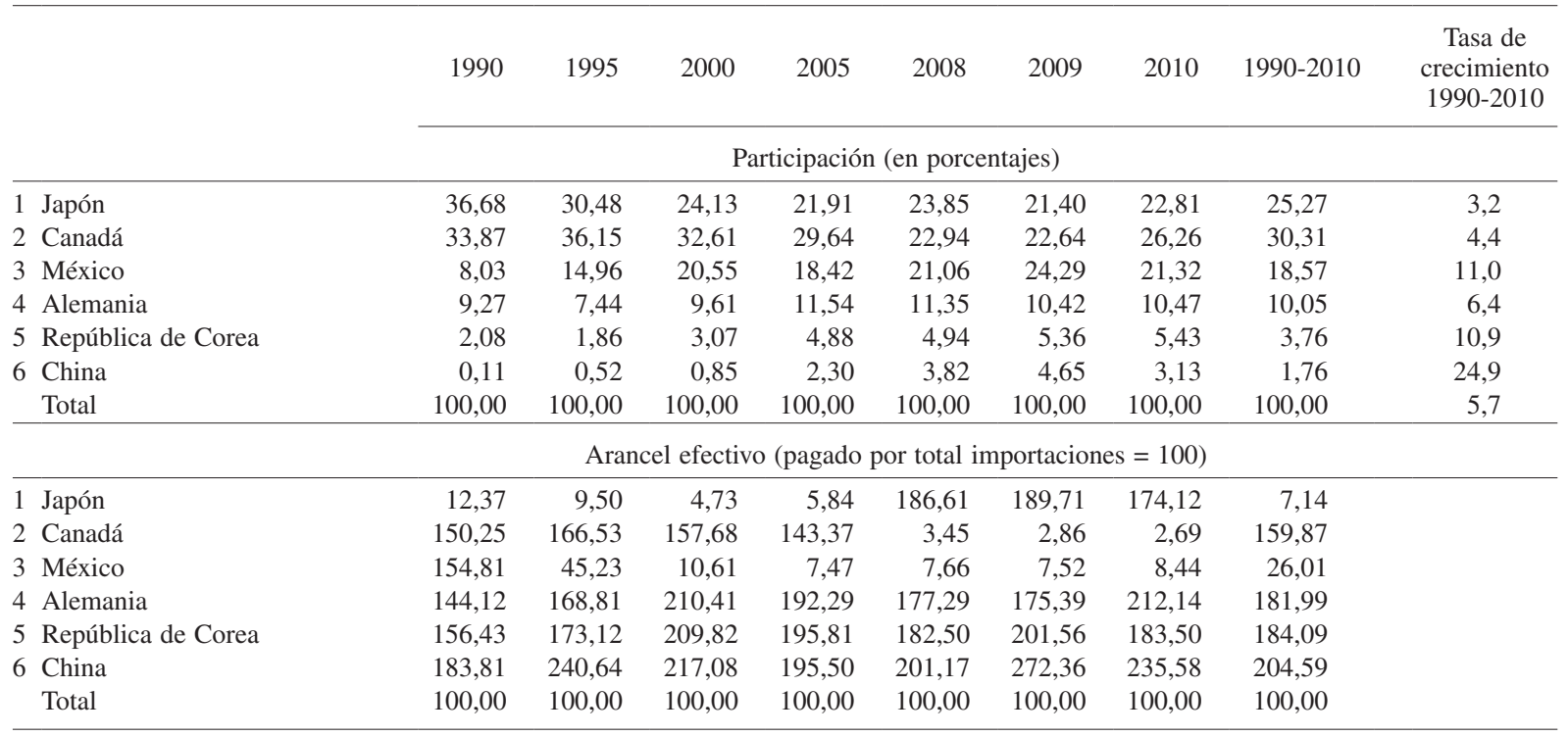

Fuente: elaborado por los autores sobre la base de datos de la Comisión de Comercio Internacional de los Estados Unidos, 2011.

exportaciones como el comercio y las inversiones - excepto en el mercado interno- crecieron notablemente.

iii) Las empresas estadounidenses en México son, sin lugar a dudas, los mayores productores y exportadores. Las "tres grandes" (General Motors, Chrysler y Ford) representaban mucho más del $60 \%$ antes de la firma del TLCAN y el 52,4\% en 2009.

iv) La cadena autopartes-automotriz mexicana atrajo más de 10.000 millones de dólares en inversión extranjera directa (EID) en el período 2000-2010 y constituye uno de los principales actores en virtud de los conocimientos adquiridos en varias décadas de inversiones, comercio, capacitación y sistemas de abastecimiento extranjeros; de las nuevas formas de organización de las empresas locales; de las relaciones con institutos de educación superior, y de algunas iniciativas para dotar a las plantas en 17 estados mexicanos de infraestructura y servicios urbanos.

v) El desempeño exportador de México ha sido particularmente auspicioso en el segmento de las partes y componentes, donde ha sido el principal exportador a los Estados Unidos de América desde 2000 (32,83\% de las importaciones estadounidenses de repuestos en 2010). En el segmento automotor, México ocupa la tercera posición (con el 15,13\% en 2010) después del Japón (27,56\%) y el Canadá $(26,58 \%)$. En el sector de los repuestos, México mantuvo su primera posición en artículos como estructuras y sus partes, chasis y partes de la transmisión, componentes eléctricos, y motores y sus partes y piezas, mientras que China se ha convertido en el principal exportador de neumáticos y tubos.

A diferencia de la cadena hilo-textiles-confección, la cadena autopartes-automotriz se encuentra todavía en otra fase de integración en la zona del TLCAN. Mientras que la primera está perdiendo terreno en la región y sobre todo en los Estados Unidos de América, en la segunda la integración entre México y ese país ha continuado. Esta tendencia también se refleja en la gran participación mexicana en las importaciones estadounidenses y en la todavía creciente IED de empresas estadounidenses en ese país. Sin embargo, existen también varias tendencias regionales que podrían crear a corto plazo situaciones similares a las observadas con respecto a la cadena hilo-textiles-confección en los últimos 10 años (Dussel Peters, 2010b). En primer lugar, la producción del TLCAN se retrajo drásticamente en 2008-2010, en tanto que la producción de Asia y China parece ser invencible a mediano plazo. En segundo lugar, además de la crisis financiera y tecnológica de las "tres grandes" empresas 
en el lapso 2008-2010, estas han perdido una parte importante del mercado mexicano, como lo han hecho los Estados Unidos de América en las importaciones totales de la cadena autopartes-automotriz. Así, dicha cadena no solo se ha reducido en términos absolutos en la zona del TLCAN, sino que también ha sido superada por sus competidores de Asia y China. Este último país todavía no ha comenzado a exportar significativamente automóviles o — para todos los efectos prácticosautopartes, pues el consumo interno se ha incrementado más de un $25 \%$ en los últimos cinco años, tasa de crecimiento que no puede continuar. El impacto de las futuras exportaciones de China a un nivel de alrededor del $30 \%$ de su producción, basado en niveles que exceden los 20 millones de vehículos, será considerable en todo el mundo y en la zona del TLCAN.

\section{V}

\section{Resumen y alternativas de políticas}

El análisis realizado en este trabajo sugiere que el TLCAN ha pasado por dos etapas diferentes. En la primera (19942000), la región también se integró en forma profunda, a raíz del comercio, las inversiones, las normas de origen y segmentos específicos de cadenas industriales, como la cadena autopartes-automotriz y la cadena hilotextiles-confección. En esta primera etapa, el TLCAN evolucionó de acuerdo con algunas de las previsiones y estimaciones señaladas en el estudio de la literatura ofrecido en la segunda sección del presente trabajo: en general, la región creció en términos de PIB, comercio, inversión, empleo y salarios, entre otras variables, y el comercio intraindustrial también aumentó en forma considerable. Mientras que algunas de las brechas entre los Estados Unidos de América y México se iban cerrando gradualmente, esto era cierto solo para una pequeña parte de la polarizada estructura territorial y socioeconómica del país azteca. Incluso en segmentos de la industria mexicana que estaban muy integrados en el TLCAN, ese proceso de integración no se tradujo en un proceso más amplio que promoviera encadenamientos hacia delante y hacia atrás en México. En la segunda etapa (a partir de 2000 en adelante), el TLCAN se ha ido deteriorando en términos de comercio, inversión y comercio intraindustrial, entre otras variables, y aparentemente tanto México como los Estados Unidos de América están perdiendo terreno ante terceros países como China.

La primera parte del análisis revela que desde el ingreso de China a la OMC en 2001 y hasta 2010, ese país aventajaba a México en el mercado estadounidense y comenzaba a competir con los Estados Unidos de América en el mercado mexicano. Se encontraron 53 sectores del mercado mexicano en que la participación estadounidense disminuye a medida que China avanza, lo que aparentemente permitiría a México incrementar su eficiencia y volverse más competitivo en los mercados estadounidenses. Sin embargo, el país azteca también está perdiendo participación en esos 53 sectores del mercado de los Estados Unidos de América, que representan el $49 \%$ de sus exportaciones a dicho mercado. Para examinar con más detalle esas tendencias en la economía mexicana se utilizan dos estudios de caso.

En la segunda parte del trabajo se destacan los cambios en la competitividad durante las diferentes etapas del TLCAN. El análisis del comercio muestra claramente el aumento de la participación mexicana en las importaciones estadounidenses, hasta quedar en segundo lugar después del Canadá en 2001-2004, para luego ser desplazada por China. La participación de los Estados Unidos de América —-tradicionalmente el principal socio comercial de México- en las importaciones mexicanas disminuyó de más del $75 \%$ en los primeros cinco años después de la entrada en vigor del TLCAN a menos del $50 \%$ desde 2009. Como evidencian distintos cálculos, China constituye en ambos casos el factor principal de esa desintegración. La penetración de los productos chinos en los 20 principales rubros de exportación de México a los Estados Unidos de América y viceversa se ha incrementado notablemente desde 2000. La participación estadounidense en las exportaciones mexicanas pasó del $72 \%$ al $41,54 \%$ en el período 2000-2009, mientras que la de China se acrecentó del 1,09\% al 17,83\%. En total, el $96 \%$ de las exportaciones estadounidenses a México y el $81 \%$ de las exportaciones mexicanas a los Estados Unidos de América están bajo "amenaza", según se la define en este documento. En última instancia se examinan los casos de "triple amenaza", es decir, de los sectores del mercado mexicano en que la participación estadounidense disminuye a medida que la de China crece y de aquellos sectores del mercado estadounidense 
en que la participación mexicana se aminora en favor de China.

Los dos estudios de caso ilustran las etapas claramente definidas por las que el TLCAN ha pasado desde 1994. La cadena hilo-textiles-confección refleja la profunda integración de la organización industrial y a nivel de empresas entre México y los Estados Unidos de América. Desde una perspectiva mexicana, se trata de un sector simbólico de la integración con su vecino del norte: es un sector muy dinámico, orientado a la exportación e intensivo en mano de obra, que depende en gran medida de importaciones desde los Estados Unidos de América y que producía un superávit comercial (sorprendentemente convertido en un déficit desde 2005) basado en importaciones masivas de partes y componentes y exportaciones de prendas de vestir terminadas y ensambladas. No obstante, el sector registró una pérdida de más del $50 \%$ de sus puestos de trabajo en el período 2000-2010 y atraviesa una profunda crisis en toda la región: los efectos de los incentivos del TLCAN han cesado y tanto en México como en los Estados Unidos de América se han perdido cientos de miles de empleos en esa década. La erosión de las normas de origen del TLCAN, la firma de otros acuerdos de libre comercio desde que este entró en vigor y la competencia con Asia y China tuvieron graves consecuencias dentro del TLCAN: la participación china en las importaciones de los Estados Unidos de América creció del 12\% al 42,1\% en 2000-2010, mientras que la de México se redujo del $13,22 \%$ al $6,51 \%$. La crisis y la pérdida de competitividad cada vez mayor de insumos clave para la cadena hilo-textiles-confección, en particular las fibras sintéticas, ha afectado profundamente a la producción y la exportación de México a los Estados Unidos de América, si bien todavía mantiene una participación considerable en las exportaciones de fibras naturales como el algodón y telas como el dril.

La cadena autopartes-automotriz difiere de la de hilotextiles-confección en que, hasta ahora, la competencia de China ha sido bastante limitada. Si bien este país se convirtió en el principal productor de automóviles en 2010 (casi la cuarta parte de los vehículos en todo el mundo y más del doble de la cifra de los Estados Unidos de América), el 100\% de su producción (además de las importaciones) se destina al consumo interno. Sin embargo, como consecuencia de las inversiones masivas del sector público chino, se están integrando cada vez más nuevas marcas chinas con tecnologías de creciente sofisticación, que representan casi el $40 \%$ de la producción total de vehículos. Muy pronto China comenzará a competir con los vehículos en América Latina, México y los Estados
Unidos de América, de modo que este sector podría ser muy relevante en términos de respuestas de políticas en la zona del TLCAN con respecto a las relaciones entre los miembros del tratado y a las relaciones bilaterales entre México y los Estados Unidos de América. Las políticas estadounidenses impulsadas en 2008-2009 reflejaron su importancia estratégica. En la actualidad, México es uno de los principales proveedores y actores de este sector en los Estados Unidos de América, en tanto que China todavía está rezagada en ese sentido; asimismo, el país azteca es aún el principal proveedor de autopartes para el TLCAN y los Estados Unidos, sobre todo de estructuras y sus partes, chasis y partes de la transmisión, componentes eléctricos y motores y sus partes y piezas, mientras que China se ha convertido en el principal exportador de neumáticos y tubos y se prevé que aumentará su participación en todos los otros segmentos de la cadena.

De este análisis derivan varias recomendaciones de políticas. Por una parte, existen varios argumentos relevantes para profundizar el marco de política regional y del tLCan. Desde el año 2000, China ha modificado intensamente el marco de integración territorial y socioeconómica establecido por el TLCAN, con enormes efectos en la producción, el comercio, el empleo y los salarios, entre otras variables. El análisis agregado de este trabajo, así como los dos estudios de caso, revelan que en muchas cadenas de valor agregado México y los Estados Unidos de América se hallan profundamente integrados. La pregunta es cuándo comenzarán los responsables de la formulación de las políticas a proponer una agenda de desarrollo regional a corto, mediano y largo plazo con una referencia explícita a Asia y China.

En primer lugar, las autoridades de las naciones del TLCAN harían bien en identificar sectores estratégicos que se encuentran altamente integrados en la región y políticas estructurales para incrementar su competitividad y aumentar su integración. El TLCAN tiene diversos foros e instituciones que podrían reforzarse con ese propósito, incluido el Banco de Desarrollo de América del Norte (BDAN). Mientras que el Banco de Desarrollo de China ha desempeñado un papel fundamental en la provisión de crédito para el desarrollo y la expansión de las empresas exportadoras chinas, el BDAN ha jugado un papel secundario, limitado a proyectos de agua, saneamiento y similares. Se podría retomar la idea original de que el BDAN serviría al desarrollo regional y brindaría asistencia para el ajuste (Fishlow, Robinson e Hinojosa-Ojeda, 1991).

En segundo lugar, las negociaciones bilaterales directas entre el TLCAN y China parecen inevitables. Si 
bien ambas partes podrían lograr resultados importantes en reuniones y rondas bilaterales, hay temas estrictamente regionales que exceden a cualquier agenda bilateral. Como se observó en los dos estudios de caso, las estructuras integradas a nivel regional requieren respuestas regionales, pues de lo contrario las políticas concretas serán demasiado generales y obsoletas.

En tercer lugar, esas políticas de competitividad regional deben concebirse e implementarse con cierta urgencia: como se observó en los estudios de caso, las estructuras, la organización industrial, el comercio, la inversión y el empleo se están trasladando rápidamente desde la región hacia Asia y China. En solo unos pocos años los respectivos segmentos de interés pueden haber desaparecido por completo. Desde otro punto de vista, comenzar un diálogo entre el TLCAN y China también podría contribuir a reducir la tensión en las relaciones entre los Estados Unidos de América y China y entre México y China, permitiendo un diálogo a largo plazo en el marco institucional del TLCAN.

En cuarto lugar, la cadena hilo-textiles-confección revela que en el futuro la profundización de la integración en la zona del TLCAN debe ir más allá de los aranceles, visto que estos solo surtieron efecto hasta fines de los años noventa. Las futuras estrategias de una agenda de desarrollo regional deberán concentrarse en la producción de insumos clave para toda la cadena (nuevos materiales, equipos y telas, y otros insumos para los sectores de artículos sintéticos, entre otros), el mejoramiento de los canales de distribución, el transporte, la creación de nuevas marcas y la incorporación de nuevas técnicas de producción (para mejorar, por ejemplo, la forma modular de producción de prendas de vestir y adoptar las nuevas modalidades de embalaje completo). Los casos exitosos de integración relativos a las fibras naturales podrían servir como base para los responsables de la formulación de políticas en las instituciones del TLCAN en cada uno de los países de la región.

En quinto lugar, la cadena autopartes-automotriz no ha enfrentado hasta ahora una dura competencia de China debido a sus particularidades en ese país, que incluyen la producción explosiva relativamente reciente y el consumo interno aún más alto, además del rápido proceso de aprendizaje por parte de los fabricantes chinos. La experiencia con otras cadenas (incluidas la de productos electrónicos y la de hilo-textiles-confección) indica, sin embargo, que China comenzará a exportar significativamente automóviles en el corto plazo. Los tres países del TLCAN (individualmente y como región) deberían entonces estudiar la mejor manera de prepararse para esta nueva y dura competencia. Las negociaciones regionales con China, específicamente con respecto a esta cadena, podrían anticiparse a futuras tensiones comerciales.

Todas las propuestas de políticas sugeridas podrían incluir una combinación de políticas comerciales, industriales, de investigación y desarrollo (I+D) y fiscales, e incentivos desde una perspectiva regional además de las políticas nacionales y las respectivas negociaciones con China. Las decisiones de alcance nacional —como ha sido el caso hasta ahora - son claramente insuficientes tanto en términos de competitividad como en las negociaciones con China y no tienen en cuenta la integración regional actual en el marco del TLCAN.

\section{Bibliografía}

amda/Amia/Ina (Asociación Mexicana de Distribuidores de Automotores/Asociación Mexicana de la Industria Automotriz/ Industria Nacional de Autopartes) (2009), El sector automotriz. en México ante la crisis financiera y económica internacional, Mexico, D.F., marzo.

Arroyo Picard y otros (1993), Tratado de Libre Comercio de América del Norte. Análisis, crítica y propuesta, México, D.F., Red Mexicana de Acción Frente al Libre Comercio.

Baer, Delal M. (1991), "North American free trade", Foreign Affairs, vol. $70, \mathrm{~N}^{\circ} 4$, Council on Foreign Affairs.

Bancomext (Banco Nacional de Comercio Exterior) (1999), "Análisis sectorial. Computadoras y componentes" [en línea] http:॥ mexico.businessline.gob.mx/espa/sectorial/notas_tec_electrico/.

Blázquez-Lidoy, Jorge, Javier Rodríguez y Javier Santiso (2006), "¿Ángel o demonio? Los efectos del comercio chino en los países de América Latina", Revista de la CEPAL, № 90 (LC/G.2323-P), Santiago de Chile, diciembre.

Burfisher, Mary, Sherman Robinson y Karen Thierfelder (2001), "The impact of NAFTA on the United States", Journal of Economic Perspectives, vol. 15, $\mathrm{N}^{\circ} 1$, Nashville, Tennessee, American Economic Association.
Caballero Urdiales, Emilio (coord.) (1991), El Tratado de Libre Comercio. México, Estados Unidos, Canadá, México, D.F., Facultad de Economía, Universidad Nacional Autónoma de México.

CANACINTRA (Cámara Nacional de la Industria de Transformación) (1994), La nueva política industrial, México, D.F.

Cárdenas Castro, Lorena y Enrique Dussel Peters (2011), "El comercio intraindustrial en México: Un comparativo entre China y Estados Unidos", Comercio Exterior, vol. 61, N 4, México, D.F., Banco Nacional de Comercio Exterior (Bancomext). (2007), "México y China en la cadena hilo-textil-confección en el mercado de Estados Unidos", Comercio Exterior, vol. 57, $\mathrm{N}^{\circ}$ 7, México, D.F., Banco Nacional de Comercio Exterior (Bancomext).

Сво (Oficina de Presupuesto del Congreso) (1993), “A Budgetary and Economic Analysis of the North American Free Trade Agreement", Washington, D.C. [en línea] http://www.cbo.gov/ publication/20871.

Comisión de Comercio Internacional de los Estados Unidos (1992), "Economy wide modeling of the economic implications of a FTA with Mexico and a NAFTA with Canada and Mexico", USITC Publication, $\mathrm{N}^{\circ}$ 2516, Washington, D.C. 
(1990), "Review of trade and investment liberalization measures by Mexico and prospects for future United States-Mexico relations", USITC Publication, vol. 2326, Washington, D.C.

DOF (Diario Oficial de la Federación) (2003), "Decreto para el apoyo de la competitividad de la industria automotriz terminal y el impulso al desarrollo del mercado interno de automóviles", 31 de diciembre [en línea] http://diariooficial.segob.gob.mx/ nota_detalle.php?codigo $=5121961 \&$ fecha $=30 / 11 / 2009$.

Donahue, Thomas R. (1991), "Statement of T.R. Donahue, SecretaryTreasurer, American Federation of Labor and Congress of Industrial Organizations before the Committee on Finance, United States Senate on the Proposed U.S.-Mexico Free Trade Negotiations", 6 de febrero.

Dussel Peters, Enrique (2010a), Políticas e instrumentos para profundizar la integración regional de la industria del vestido en la zona del TLCAN, México, D.F., Cámara Nacional de la Industria del Vestido (CNIV)/Centro de Estudios China-México/ Facultad de Economía/Universidad Nacional Autónoma de México.

(2010b), "¿Cooperación o competencia en la cadena autopartes-automotriz entre China y México?", Hacia un diálogo entre México y China. Dos y tres décadas de cambios socioeconómicos, Enrique Dussel Peters y Yolanda Trápaga Delfín (eds.), México, D.F., Senado de la República.

(2004), "La competitividad de la industria maquiladora de exportación en Honduras. Condiciones y retos ante el CAFTA" (LC/MEX/R.853), México, D.F., sede subregional de la CEPAL en México.

(2000), Polarizing Mexico. The Impact of Liberalization Strategy, Boulder, Colorado, Lynne Rienner Publishers.

Dussel Peters, Enrique y Lorena Cárdenas Castro (2011), "El comercio intraindustrial en México: Un comparativo entre China y Estados Unidos", Comercio Exterior, vol. 61, № 4, México, D.F., Banco Nacional de Comercio Exterior (Bancomext).

Dussel Peters, Enrique, Clemente Ruiz Durán y Taeko Taniura (1997), "Changes in industrial organization of the Mexican automobile industry by economic liberalization", Joint Research Program Series, $N^{\circ} 120$, Instituto de Economías en Desarrollo.

Erzan, Refik y Alexander Yeats (1992), "Free trade agreements with the United States: what's in it for Latin America?", Policy Research Working Paper Series, $\mathrm{N}^{\circ}$ 827, Washington, D.C., Banco Mundial.

Feenstra, Robert (2007), "Trade liberalisation and export variety: a comparison of Mexico and China", World Economy, vol. 30, $\mathrm{N}^{\circ} 1$, Wiley Blackwell, enero.

Fishlow, Albert, Sherman Robinson y Raúl Hinojosa-Ojeda (1991), "Proposal for a North American regional development bank and adjustment fund", Proceedings, Dallas, Banco de la Reserva Federal de Dallas.

Frederick, Stacey y Gary Gereffi (2009), "Review and analysis of protectionist actions in the textile and apparel industries", documento preparado para el Banco Mundial y el Centro de Investigación en Economía y Política.

Gallagher, Kevin P., Juan Carlos Moreno-Brid y Roberto Porzecanski (2008), "The dynamism of Mexican exports: lost in (Chinese) translation?", World Development, vol. 36, № 8, Amsterdam, Elsevier.

Grinspun, Ricardo y Maxwell Cameron (1993), The Political Economy of North American Free Trade, Nueva York, St. Martin's Press.

Hufbauer, Gary y Jeffrey Schott (2005), NAFTA Revisited: Achievements and Challenges, Washington, D.C., Instituto de Economía Internacional.
(1993), NAFTA: An Assessment, Washington, D.C., Peterson Institute for International Economics.

INEGI (Instituto Nacional de Estadística, Geografía e Informática) (2010a), La industria textil y del vestido en 2009, México, D.F.

(2010b), La industria automotriz en México, México, D.F.

INFORUM (Interindustry Economic Research Fund) (1991), "Industrial Effects of a Free Trade Agreement Between Mexico and the USA", Washington, D.C., Departamento del Trabajo.

Kehoe, Timothy (1994), "Assessing the economic impact of North American free trade", The NAFTA Debate: Grappling with Unconventional Trade Issues, M.D. Baer y S. Weintraub (eds.), Boulder, Colorado, Lynne Rienner Publishers.

Kopinak, Kathy (1993), "The maquiladorization of the Mexican economy", The Political Economy of North American Free Trade, Ricardo Grinspun y Max Cameron (eds.), Nueva York, St. Martins.

Lall, Sanjaya y John Weiss (2005), "China's competitive threat to Latin America: an analysis for 1990-2002", Oxford Development Studies, vol. 33, $\mathrm{N}^{\circ} 2$, Taylor \& Francis.

Lande, Stephen L. (1991), "Textiles: U.S. perspective", U.S.-Mexican Industrial Integration: The Road to Free Trade, Sidney Weintraub, Luis Rubio F. y Alan D. Jones (eds.), Boulder, Colorado, Westview Press.

Lederman, Daniel, Marcelo Olarreaga y Eliana Rubiano (2008), "Trade specialization in Latin America: the impact of China and India", Review of World Economics, vol. 144, $\mathrm{N}^{\circ} 2$, Springer.

Monitor de la Manufactura Mexicana (2012), vol. 8, № 9, México, D.F

Oficina de Estadísticas Laborales (2009) [en línea] http://data.bls. gov/PDQ/outside.jsp?survey=ip.

Piore, Michael (1991), "Los estándares sociales en México y las estrategias empresariales de Estados Unidos en un mercado integrado de América del Norte", México ante el libre comercio con América del Norte, Gustavo Vega Cánovas (coord.), México, D.F., El Colegio de México/Universidad Tecnológica de México.

Piore, Michael y Sabel (1984), The Second Industrial Divide, Nueva York, Basic Books.

Rodrik, Dani (2010), "The return of industrial policy", Project Syndicate. SE (Secretaría de Economía) (2011), Industria automotriz. Monografía, México, D.F., Dirección General de Industrias Pesadas y de Alta Tecnología.

(2008), Agenda para la competitividad de la industria automotriz en México, México, D.F.

SECOFI (Secretaría de Comercio y Fomento Industrial) (1992), “¿Qué es el TLC? Extractos del mensaje del Presidente de la República, Carlos Salinas de Gortari, al pueblo de México con motivo de la conclusión de las negociaciones del Tratado de Libre Comercio", México, D.F., 12 de agosto.

Shelburne, Robert C. (1991), "The North American Free Trade Agrement: comparisons with and lessons from Southern EC enlargement", Economic Discussion Paper, $\mathrm{N}^{\circ} 39$, Washington, D.C., Departamento del Trabajo.

Sturgeon, Timothy, Johannes Biesebroeck y Gary Gereffi (2008), "Value chains, networks and clusters: reframing the global automotive industry", Working Paper Series, Cambridge, Industrial Performance Center.

VanGrasstek, Craig y Gustavo Vega (1992), "The North American Free Trade Agreement: a regional model?", The Premise and the Promise: Free Trade in the Americas, Sylvia Saborio (ed.), Washington, D.C., Consejo de Desarrollo de Ultramar.

Weintraub, Sidney (1991), "Regionalism and the GATT: The North American initiative", SAIS Review, vol. 11, $\mathrm{N}^{\circ} 1$, Baltimore, Project MUSE. 